\title{
Reference 1D and 2D electrophoresis maps for potential disease related proteins in milk whey from lactating buffaloes and blood serum from buffalo calves (Water buffalo, Bubalus bubalis)
}

\author{
André M. Santana ${ }^{\mathrm{a}, *}$, Funmilola C. Thomas ${ }^{\mathrm{b}}$, Daniela G. Silva ${ }^{\mathrm{a}}$, Eilidh McCulloch ${ }^{\mathrm{c}}$, \\ Ana M.C. Vidal $^{\mathrm{d}}$, Richard J.S. Burchmore ${ }^{\mathrm{e}}$, José J. Fagliari ${ }^{\mathrm{a}}$, Peter D. Eckersall ${ }^{\mathrm{c}}$ \\ a Department of Veterinary Clinic and Surgery, School of Agricultural and Veterinary Sciences, São Paulo State University (FCAV/UNESP), Jaboticabal, SP, Brazil \\ ${ }^{\mathrm{b}}$ Department of Veterinary Physiology and Pharmacology, College of Veterinary Medicine, Federal University of Agriculture, Abeokuta, Nigeria \\ ${ }^{\mathrm{c}}$ Institute of Biodiversity, Animal Health and Comparative Medicine, College of Medical, Veterinary and Life Sciences, University of Glasgow, Glasgow, United Kingdom \\ ${ }^{\mathrm{d}}$ Department of Veterinary Medicine, Faculty of Animal Science and Food Engineering, University of São Paulo (FZEA/USP), Pirassununga, SP, Brazil \\ ${ }^{\mathrm{e}}$ Institute of Infection, Immunity and Inflammation, Glasgow Polyomics Facility, College of Medical, Veterinary and Life Sciences, University of Glasgow, Glasgow, United \\ Kingdom
}

\section{A R T I C L E I N F O}

\section{Keywords:}

Acute phase proteins

Haptoglobin

Mastitis

Protein map

Proteomics

Salmonellosis

\begin{abstract}
A B S T R A C T
The aim of this study was to identify potential disease related proteins in milk whey of lactating buffaloes and blood serum of buffalo calves, in order to define a reference electrophoresis map for 1-DE and 2-DE. Additionally, changes in some protein patterns from buffalo calves during salmonellosis and lactating buffaloes during mastitis are presented. Milk samples were collected and distributed into groups: Milk samples from healthy buffaloes (SCC $<100.000$ cells $/ \mathrm{ml}$, negative microbiology and CMT) $(\mathrm{G} 1, \mathrm{n}=5)$ and buffaloes with subclinical mastitis (SCC > 500.000 cells $/ \mathrm{ml}$, positive microbiology and CMT) (G2, $\mathrm{n}=5$ ). Blood samples from buffalo calves $(n=6)$ were collected, and three calves were experimentally infected with Salmonella Dublin and samples analyzed before (M0) and $72 \mathrm{~h}$ after inoculation (M1). 1-DE was accomplished by loading $10 \mu \mathrm{g}$ of TP into SDS-PAGE, stained with Coomassie blue. 2-DE was accomplished by loading $200 \mu \mathrm{g}$ of TP into $11 \mathrm{~cm}$, pH 3-10 non-linear IPG strips, followed by SDS-PAGE, stained with Coomassie blue. Protein bands/spots were excised, subjected to tryptic in-gel digestion and analyzed by LC/ESI-MS/MS. Protein identity was assigned using NCBI databases. After bands/spots from 1-DE and 2-DE were analyzed, a protein map with 35 and 40 different identified proteins in blood serum and milk whey, respectively, was generated. Significant changes in patterns of haptoglobin were observed in buffalo calves with salmonellosis and in patterns of IgLC, $\beta$-lactoglobulin and $\alpha$ lactalbumin of lactating buffaloes during mastitis. The establishment of a protein map for 1-DE and 2-DE, identifying potential disease related proteins, can help to address alterations during diseases in buffaloes.
\end{abstract}

\section{Introduction}

Among domestic animals, the water buffalo (Bubalus bubalis), particularly the river buffalo (subfamily Bovinae), holds great potential for animal production. Approximately $15 \%$ of the milk supply in the world is sourced from buffaloes and the Asian continent, with a buffalo population near to 150 million animals, is the major producer of buffalo milk. In Brazil, the buffalo is distributed in all states with an estimated population of 1.5 million animals. The southeast region $(10.2 \%$ of all animals) has the largest concentration of farms specialized in buffalo milk production destined for the manufacture of milk derivatives, for which Murrah and Jafarabadi breeds are the most important (MAPA,
2016).

Thus, buffalo milk production is of great importance in Brazil and other countries and studies related to milk whey and blood serum alterations due to diseases in lactating buffaloes and in newborn animals are important for the maintenance of an adequate milk production system. In this context, special attention has been given to acute phase proteins (APP), that can be used in diagnosis, prognosis and in monitoring response to therapy, as well as in general health screening (Eckersall and Bell, 2010).

In lactating cows, APP in blood and milk have shown positive correlation with the severity of mastitis infection (Eckersall et al., 2001, 2006; Wenz et al., 2010; Buitenhuis et al., 2011; Pyörälä et al., 2011)

\footnotetext{
* Corresponding author at: Department of Veterinary Clinic and Surgery, School of Agricultural and Veterinary Sciences, São Paulo State University (FCAV/UNESP), Via de Acesso Prof. Paulo Donato Castellane s/n, Jaboticabal, SP 14884-900, Brazil.

E-mail address: andrevetms@gmail.com (A.M. Santana).
} 
Table 1

Parameters from lactating buffaloes $(n=10)$ and buffalo calves $(n=6)$ that were selected and distributed among the experimental groups.

\begin{tabular}{|c|c|c|c|c|c|}
\hline \multicolumn{6}{|c|}{ Lactating buffaloes } \\
\hline \multicolumn{6}{|c|}{ Milk whey samples from heathy buffaloes (G1) } \\
\hline Sample ID & SCC & CMT & Microbiology & Month of lactation & $\mathrm{N}^{\mathrm{o}}$ of lactations \\
\hline M1 & 21,000 & 0 & Negative & 4th & 2nd \\
\hline M2 & 21,000 & 0 & Negative & 4th & 2nd \\
\hline M3 & 28,000 & 0 & Negative & 4th & 3rd \\
\hline M4 & 22,000 & 0 & Negative & 4th & 2nd \\
\hline M5 & 24,000 & 0 & Negative & 6th & $3 r d$ \\
\hline Average & $23,200 \pm 2950$ & - & - & - & - \\
\hline \multicolumn{6}{|c|}{ Milk whey samples from buffaloes with subclinical mastitis (G2) } \\
\hline M6 & $1,845,000$ & 3 & S. intermedius & 4th & 2nd \\
\hline M7 & $8,670,000$ & 2 & S. aureus & 5th & 2nd \\
\hline M8 & $3,731,000$ & 2 & Staphylococcus sp. & 6th & $3 r d$ \\
\hline M9 & $3,487,000$ & 2 & Staphylococcus sp. & 6th & $3 \mathrm{rd}$ \\
\hline M10 & 615,000 & 1 & Staphylococcus sp. & 6th & 3rd \\
\hline Average & $3,669,600 \pm 3,070,051$ & - & - & - & - \\
\hline \multirow[t]{2}{*}{ Animal ID } & Buffalo calves & & & & \\
\hline & Age (days)/gender & Weigh (Kg) & Microbiology & $\mathrm{RT}\left({ }^{\circ} \mathrm{C}\right)$ & FC score \\
\hline S1M0 & $26 / \mathrm{F}$ & 42.8 & Negative & 37.9 & 0 \\
\hline S2M0 & $22 / \mathrm{M}$ & 80.4 & Negative & 38.8 & 0 \\
\hline S3M0 & $12 / \mathrm{M}$ & 64.4 & Negative & 39.0 & 0 \\
\hline S4M0 & $26 / \mathrm{M}$ & 63.2 & Negative & 38.3 & 0 \\
\hline S5M0 & $29 / \mathrm{M}$ & 63.1 & Negative & 37.3 & 0 \\
\hline S6M0 & $30 / \mathrm{F}$ & 81.7 & Negative & 37.8 & 0 \\
\hline Average & $24.2 \pm 6.6$ & $65.9 \pm 14.2$ & - & $38.2 \pm 0.6$ & 0 \\
\hline S1M1 & - & - & S. Dublin & 40.3 & 1 \\
\hline S2M1 & - & - & $S$. Dublin & 41.8 & 1 \\
\hline S3M1 & - & - & S. Dublin & 41.4 & 2 \\
\hline Average & - & - & - & $41.2 \pm 0.8$ & $1.33 \pm 0.58$ \\
\hline
\end{tabular}

RT, Rectal Temperature; FC score, Feces Consistency score.

M1 to M5: Milk whey samples from heathy buffaloes (G1); M6 to M10: Milk whey samples from buffaloes with subclinical mastitis(G2).

S1M0 to S6M0: Blood serum samples from buffalo calves before inoculation (M0).

S1M1, S2M1, S3M1: Blood serum samples from buffalo calves $72 \mathrm{~h}$ after inoculatiom with $10^{8} \mathrm{CFU}$ of $S$. Dublin (M1).

and have been shown to be reliable indicators of inflammation and useful to screen quarters for intramammary inflammation. In buffaloes, studies with alterations in APP in the milk during mastitis are scarce, but have already showed that haptoglobin and serum amyloid A are good milk indicators for the detection of streptococcal and staphylococcal clinical and sub-clinical mastitis (Kumar et al., 2014).

When analyzing newborns buffalo calves, the first month of life is critical, as morbidity and mortality rates are high. The major causes are diarrhea and pneumonia (Khan et al., 2009; Anwarullah et al., 2014; Naag et al., 2015) caused by various pathogens (Anwarullah et al., 2014; Silva et al., 2015) and are responsible for great economic losses. In this context, APP have also shown to be of great value, since alterations in serum concentrations of APP fibrinogen, ceruloplasmin and haptoglobin in diarrheic newborn buffaloes infected with Salmonella Thyphimurium (Clemente et al., 2016) have been reported.

Milk whey and blood serum are complex mixtures of a few high abundance proteins and a wide selection of low abundance protein components (Ferreira et al., 2013) that could be utilized for diagnosis and prognosis purposes. Thus, in addition to the APP, other proteins related to defence/immunity, lipid and protein transport and metabolism, enzyme regulation, cell-to-cell signaling, among others, could be altered during the disease process. In this sense, proteomic studies for biomarker investigations have, over the past decade, developed the use of gel and gel-free methodologies based on liquid chromatography analyses (Schiess et al., 2009), among others. In this context, the use of proteomic methodologies such us 1D-electrophoresis (1-DE), 2D-electrophoresis (2-DE) and gel-free analyses (label-free and label-based methods) to obtain a complete characterization of host responses during infections could lead to the identification of a pattern of biomarkers indicative of diseases.

The use of 2-DE combined with LC/ESI-MS/MS (liquid chromatography coupled with electrospray ionization tandem mass spectrometry) can be a powerful strategy for the identification of proteins. However, little information is known, in healthy and diseased buffalo blood serum and milk whey, about which proteins are detected and how these proteins behave in 1-DE and 2-DE gels (D'Auria et al., 2005; D'Ambrosio et al., 2008; Jena et al., 2015). In contrast, several proteomic analyses with relation to healthy cattle and, as an example, cattle with mastitis have been performed using 2-DE and gel-free analyses such as label-free and label-based methods (Boehmer et al., 2010a, 2010b; Danielsen et al., 2010; Alonso-Fauste et al., 2012; Thomas et al., 2016a, 2016b; Mudaliar et al., 2016).

A combined approach based on 1-DE and 2-DE with LC/ESI-MS/MS can help to identify a great amount of disease related proteins such us APP and defence/immunity-related proteins, as well as high abundance proteins, serpins, apolipoproteins and proteins with various other functions that could participate in metabolic pathways of interest. In addition, mapping these proteins in 1-DE and 2-DE gels is of great importance for buffaloes species, as it may serve as a starting point for other studies in buffaloes related to protein changes during diseases and other physiological conditions. Therefore, considering the lack of published works available in buffalo proteomics, the aim of this study was to identify, in milk whey of lactating buffaloes and blood serum of buffalo calves, proteins with potential to be differentially expressed during disease and other physiological conditions in buffaloes. Additionally, changes in patterns of APP haptoglobin in the blood serum of buffalo calves during salmonellosis, and of immunoglobulin light chain, $\beta$-lactoglobulin and $\alpha$-lactalbumin in milk whey of lactating buffaloes during mastitis were studied. 


\section{Materials and methods}

This research was approved by the Ethics Committee on Animal Use of "Faculdade de Ciências Agrárias e Veterinárias, UNESP" (Protocol n 010885-08 and $n^{\circ}$ 017094/12).

\subsection{Distribution of experimental groups for defining a reference} electrophoresis map for 1-DE and 2-DE and for analyzing changes in protein patterns during mastitis and salmonellosis

\subsubsection{Experimental groups designed for lactating buffaloes}

Milk samples were collected from lactating Jafarabadi buffaloes housed in a semi-intensive system with a diet based on roughage, on farms with commercial herds localized in São Paulo state, Brazil. All samples were collected during the dry season of the year (winter, between June and August), when animals were fed with chopped sugar cane and supplemented with protein concentrate.

Individual milk samples from each udder-quarter were collected. After collection, milk samples were submitted to CMT, SCC and microbiological evaluation, and distributed into two experimental groups: G1 ( $n=5$, sample ID: M1 to M5): individual udder-quarter milk samples from healthy buffaloes (SCC $<100.000$ cells/ml, negative microbiology and CMT); G2 ( $=5$, sample ID: M6 to M10): individual udderquarter milk samples from buffaloes with subclinical mastitis (SCC $>500.000$ cells $/ \mathrm{ml}$, positive microbiology and CMT). All information of milk samples used to perform this study is listed in Table 1.

SCC was performed in the "Laboratório de Fisiologia da Lactação Lair Antônio de Souza (LAFLA), Clínica do Leite, Departamento de Produção Animal da Escola Superior de Agricultura Luiz de Queiroz, USP/Piracicaba, SP" using a automatic electronic infrared counter (Somacount 300, Bentley Instruments Incorporated, Minnesotta, EUA).

Bacterial culture and identification of bacteria was performed in the "Laboratório Multiusuário de Saúde Animal e Segurança Alimentar, Departamento de Medicina Veterinária, Faculdade de Zootecnia e Engenharia de Alimentos, Universidade de São Paulo (FZEA/USP), Pirassununga, SP, Brazil". Aseptically collected milk was seeded in $5 \%$ defibrinated bovine blood agar and MacConkey agar at $37^{\circ} \mathrm{C}$, under aerobic conditions, with daily readings until $72 \mathrm{~h}$ (Quinn et al., 2005). The microorganisms were identified according to the morpho-tinctorial, biochemical and cultivation characteristics (Quinn et al., 1994, 2005; Trabulsi et al., 2005a, 2005b; Jorgensen et al., 2015).

\subsubsection{Experimental groups designed for newborn buffalo-calves}

Blood samples from Murrah newborn buffalo-calves (12 to 30 days old) were collected in farms located in São Paulo State, Brazil, and health status was verified by performing physical examination. Feces were analyzed to check for signs of diarrhea, blood and mucus and received feces consistency scores: 0 : normal (firm feces consistency), 1 : mild diarrhea (soft feces consistency), 2: moderate to severe diarrhea (liquid feces consistency) (Tremblay, 1990). Rectal temperature was also measured. Six calves (sample ID: S1M0, S2M0, S3M0, S4M0, S5M0 and S6M0), that had firm feces consistency (score 0) and rectal temperature below $40.0^{\circ} \mathrm{C}$, were included in the study (Table 1).

From the six calves selected, three calves were isolated from the other animals and housed in individual suspended shelters $(1.30 \mathrm{~m} \times 1.50 \mathrm{~m} \times 1.35 \mathrm{~m}$ and $0.4 \mathrm{~m}$ above the ground) at "Laboratório de Apoio à Pesquisa do Departamento de Clínica e Cirurgia Veterinária, FCAV, UNESP, Jaboticabal, Brazil”. These calves were then challenged orally with $10^{8} \mathrm{CFU}$ of Salmonella Dublin strain suspended in $10 \mathrm{ml}$ of BHI broth, and blood samples were collected before inoculation (S1M0, S2M0 and S3M0) and $72 \mathrm{~h}$ after inoculation (S1M1, S2M1 and S3M1) (Table 1).

Inocula for induction of experimental infection was prepared from a Salmonella Dublin sample (IOC record: 3101/03) donated by "FIOCRUZ, Rio de Janeiro, Brazil - Centro de Referência de Enterobactérias do Departamento de Bacteriologia". Inocula were prepared according to Fecteau et al. (2003). By using the Miles and Misra (1938) technique, appropriate dilutions were made to obtain the required concentration of colonies $/ \mathrm{ml}$.

Rectal swabs were collected from each animal immediately before inoculation (M0) and $72 \mathrm{~h}$ after inoculation (M1). Bacteriological culture for isolation of $S$. Dublin from the rectal swabs were performed at "Laboratório de Apoio à Pesquisa do Departamento de Clínica e Cirurgia Veterinária, FCAV, UNESP, Jaboticabal, Brazil”, according to recommendations (Santos et al., 2002). For this, three rectal swab samples collected at each moment (M0 and M1) were transferred into $10 \mathrm{ml}$ of selenite cysteine (CM699, Oxoid), tetrathionate Muller-Kauffmann (CM343, Oxoid) and Rappaport-Vassiliadis (CM866, Oxoid) selective enrichment broths and incubated at $37^{\circ} \mathrm{C}$ for $24 \mathrm{~h}$. After incubation, broths were plated in modified brilliant green agar (CM329, Oxoid) plates and incubated $\left(37^{\circ} \mathrm{C}, 24 \mathrm{~h}\right)$. From each plate, three Salmonella suggesting colonies were submitted to presumptive biochemistry tests using triple-sugar-iron agar (CM277, Oxoid) and lysine-agar (CM381, Oxoid). All the identified Salmonella colonies were submitted to slide agglutination test with poli-O, poli-H and poli-D Salmonella antiserum (Probac of Brazil, São Paulo, SP, Brazil). Positive culture for Salmonella Dublin were considered when identified Salmonella colonies were positive to the three slide agglutination tests (poli-O, poli-H and poli-D Salmonella antiserum).

\subsubsection{Reference electrophoresis maps and changes in protein patterns} during mastitis and salmonellosis

To find and identify the highest possible number of proteins of interest, reference electrophoresis maps for 1-DE and 2-DE were generated using healthy (M1-M5) and mastitic (M6-M10) milk samples $(\mathrm{n}=10)$ from the lactating buffaloes and before (S1M0, S2M0, S3M0, S4M0, S5M0 and S6M0) and after-challenge (S1M1, S2M1, S3M1) blood samples $(n=9)$ from the newborn buffalo calves.

For analyzing changes in protein patterns during mastitis and salmonellosis, statistical analysis were performed to compare $\mathrm{G} 1 \times \mathrm{G} 2$ (lactating buffaloes) and M0 × M1 (buffalo calves).

\subsection{Sample preparation for 1-DE and 2-DE}

Sample preparation for 1-DE and 2-DE were performed at "Laboratório de Apoio à Pesquisa do Departamento de Clínica e Cirurgia Veterinária, FCAV, UNESP, Jaboticabal, Brazil" and Acute Phase Laboratory, Institute of Biodiversity, Animal Health \& Comparative Medicine, Garscube Campus, University of Glasgow, UK. All milk samples listed in Table 1, meaning five milk samples from heathy buffaloes and five milk samples from udder-quarters with subclinical mastitis, were prepared to perform 1-DE and 2-DE, so that 10 individual patterns (for 1-DE) and 10 individual gels (for 2-DE) could be performed and analyzed. All animals listed in Table 1, meaning six blood samples from healthy buffalo calves (M0) + three blood samples from buffaloes calves collected $72 \mathrm{~h}$ after inoculation (M1), were also prepared to perform 1-DE and 2-DE, so that nine individual patterns (for 1-DE) and nine individual gels (for 2-DE) could be performed and analyzed.

Milk whey samples were obtained by addition of renin solution (Coalho Estrella, Chr. Hansen Brasil Ind. E Com. Ltda, Valinhos, SP, Brazil) to the milk samples (amounts of $10 \%$ renin solution $+90 \%$ milk samples), followed by centrifugation $\left(20 \mathrm{~min}, 4^{\circ} \mathrm{C}, 10,000 \times g\right)$ so that solids and caseins were removed before performing 1-DE and 2-DE. To remove salts, acetone precipitation was then carried out for each sample by adding 4 times the sample volume of ice cold $100 \%$ acetone to the samples. The sample was mixed and kept at $-20^{\circ} \mathrm{C}$ overnight. Precipitate was separated from supernatant by centrifugation at $14,000 \times g$ for $30 \mathrm{~min}$ at $4^{\circ} \mathrm{C}$. The pellets formed were then washed by mixing with ice cold $80 \%(\mathrm{v} / \mathrm{v})$ acetone and then centrifuged at $14,000 \times g$ for $30 \mathrm{~min}$ once again. This step was repeated two more times. Finally all supernatant was separated from the pellet and the 
Table 2

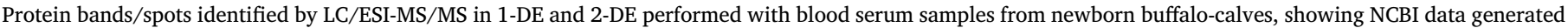
using mascot engine search.

\begin{tabular}{|c|c|c|c|c|c|c|c|}
\hline $\begin{array}{l}\text { Band/spot } \\
\text { number }\end{array}$ & $\begin{array}{l}\text { Protein identification (Accession } \\
\text { number, organism) }\end{array}$ & $\begin{array}{l}\text { Protein MASCOT SC } \\
\text { ore }^{\text {a }}\end{array}$ & Matches $^{\mathrm{b}}$ & Sequences $^{\mathrm{c}}$ & $\begin{array}{l}\text { Estimated MW } \\
\text { (Da) }\end{array}$ & ID Method & Protein function \\
\hline 1 & a2-macroglobulin (gi|594093035 BB) & $1839(0.80)$ & $162(66)$ & $52(32)$ & 165,702 & 1-DE & APP \\
\hline 2 & Ceruloplasmin (gi|594079008, BB) & $173(0.10)$ & $28(4)$ & $19(4)$ & 125,184 & 1-DE & APP \\
\hline \multirow[t]{3}{*}{3} & ITIH4 (gi|594051967, BB) & $312(0.28)$ & $49(14)$ & $26(8)$ & 99,001 & 1-DE & APP \\
\hline & Serpin A3-2 (gi|594050458, BB) & $250(0.45)$ & $18(8)$ & $12(5)$ & 40,453 & & Defence/Immunity \\
\hline & $\begin{array}{l}\text { Endopin 1b (Serpin A3-3) } \\
\text { (gi|594074015, BB) }\end{array}$ & $109(0.14)$ & $12(2)$ & $9(2)$ & 46,738 & & Defence/Immunity \\
\hline 4 & Complement C6 (gi|594107089, BB) & $107(0.03)$ & $10(1)$ & $8(1)$ & 108,221 & 1-DE & Defence/Immunity \\
\hline 5 & $\begin{array}{l}\text { Complement factor B (gi } \mid 594034465 \text {, } \\
\text { BB) }\end{array}$ & $293(0.15)$ & $32(8)$ & $17(4)$ & 86,804 & 1-DE & Defence/Immunity \\
\hline \multirow[t]{2}{*}{6} & Plasminogen (gi|594054121, BB) & $188(0.10)$ & $33(3)$ & $19(3)$ & 94,095 & 1-DE & APP \\
\hline & Gelsolin isoform b (gi|77736201, BT) & $113(0.08)$ & $7(2)$ & $6(2)$ & 80,681 & & Defence/Immunity \\
\hline \multirow[t]{2}{*}{7} & Serotransferrin (gi|594054424, BB) & $1612(0.70)$ & $90(24)$ & $36(14)$ & 79,994 & 1-DE & APP \\
\hline & $\begin{array}{l}\text { Complement C5a anaphylatoxin } \\
\text { (gi|262205546, BB) }\end{array}$ & $111(0.02)$ & $3(1)$ & $3(1)$ & 190,388 & & Defence/Immunity \\
\hline \multirow[t]{2}{*}{8} & Serotransferrin (gi|594054424, BB) & $995(0.83)$ & $90(27)$ & $34(15)$ & 79,994 & 1-DE & APP \\
\hline & Ig M heavy chain (gi|2232299, BT) & $63(0.06)$ & $2(1)$ & $2(1)$ & 47,885 & & Defence/Immunity \\
\hline \multirow[t]{2}{*}{9} & Serum Albumin (gi|594045062, BB) & $1878(2.15)$ & $207(62)$ & $48(25)$ & 71,177 & 1-DE & APP \\
\hline & $\begin{array}{l}\text { a1-antitrypsin (Serpin A1) } \\
\text { (gi| } 594050476, \mathrm{BB})\end{array}$ & $64(0.07)$ & $2(1)$ & $2(1)$ & 46,290 & & APP \\
\hline \multirow[t]{7}{*}{10} & Kininogen-2 (gi|594069549, BB) & $137(0.14)$ & $9(4)$ & $6(3)$ & 69,820 & 1-DE & Defence/Immunity \\
\hline & Endopin 2B (Serpin A3-7) & $108(0.14)$ & $5(3)$ & $3(2)$ & 46,972 & & Defence/Immunity \\
\hline & $(\mathrm{gi} \mid 38,683,423, \mathrm{BT})$ & $88(0.08)$ & $9(1)$ & $6(1)$ & 38,984 & & APP \\
\hline & $\alpha$-2-HS-glycoprotein (gi $\mid 594,069,561$, & $86(0.06)$ & $10(1)$ & $9(1)$ & 54,890 & & APP \\
\hline & $\mathrm{BB})$ & $72(0.42)$ & $5(1)$ & $1(1)$ & 8025 & & Defence/Immunity \\
\hline & $\begin{array}{l}\text { Vitamin D-binding protein } \\
\text { (gi| } 397,740,864, \mathrm{BB} \text { ) }\end{array}$ & & & & & & \\
\hline & $\begin{array}{l}\text { Ig gamma heavy chain (gi| } 126,542,085 \\
\text { CEH) }\end{array}$ & & & & & & \\
\hline 11 & $\begin{array}{l}\text { Complement factor I (gi| } \mid 594,056,114 \text {, } \\
\text { BB) }\end{array}$ & $47(0.00)$ & $2(0)$ & $2(0)$ & 71,319 & 1-DE & Defence/Immunity \\
\hline 12 & Complement C3 (gi|594,041,230, BB) & $323(0.12)$ & $38(9)$ & $17(7)$ & 188,843 & 1-DE & APP \\
\hline 13 & Complement C3 (gi $\mid 594,041,230, \mathrm{BB})$ & $176(0.08)$ & $29(6)$ & $15(5)$ & 188,843 & 1-DE & APP \\
\hline 14 & Haptoglobin (gi|595,763,483, BT) & $1085(1.21)$ & $114(35)$ & $22(12)$ & 45,676 & 1-DE & APP \\
\hline \multirow[t]{2}{*}{15} & Adiponectin (gi|114,158,576, BT) & $211(0.58)$ & $10(5)$ & $6(4)$ & 26,117 & 1-DE & Hormone, Inflamation process \\
\hline & Complement C4-A (gi $\mid 528,929,317$, BT) & $153(0.07)$ & $11(4)$ & $9(4)$ & 189,312 & & Defence/Immunity \\
\hline 16 & $\begin{array}{l}\text { Ig lambda light chain (gi } \mid 92,096,965 \text {, } \\
\text { BT) }\end{array}$ & $159(0.27)$ & $18(4)$ & $4(2)$ & 24,863 & 1-DE & Defence/Immunity \\
\hline 17 & Apolipoprotein A-I (gi|594,065,921, BB) & $726(0.81)$ & $37(8)$ & $13(6)$ & 30,232 & 1-DE & APP \\
\hline 18 & Haptoglobin (gi $\mid 283,467,275, \mathrm{BB})$ & $471(0.37)$ & $25(11)$ & $9(5)$ & 48,259 & 1-DE & APP \\
\hline 19 & Hemoglobin (gi|594,075,744, BB) & $465(1.90)$ & $27(16)$ & $13(9)$ & 25,066 & 1-DE & Transport \\
\hline \multirow[t]{2}{*}{20} & a2-macroglobulin (gi $\mid 594,093,035, \mathrm{BB})$ & $770(0.47)$ & $74(24)$ & $39(21)$ & 165,702 & 2-DE & APP \\
\hline & $\begin{array}{l}\text { Complement factor } \mathrm{H} \text { (gi| } 76,677,897 \text {, } \\
\text { BT) }\end{array}$ & $164(0.09)$ & $19(5)$ & $14(4)$ & 144,958 & & Defence/Immunity \\
\hline 21 & Ceruloplasmin (gi|296,491,101, BT) & $201(0.16)$ & $17(6)$ & $10(6)$ & 120,931 & 2-DE & APP \\
\hline 22 & Ceruloplasmin (gi| $296,491,101, \mathrm{BT}$ ) & $42(0.03)$ & $5(1)$ & $3(1)$ & 120,931 & 2-DE & APP \\
\hline 23 & $\begin{array}{l}\text { Complement factor B (gi| } 594,034,463 \text {, } \\
\text { BB) }\end{array}$ & $108(0.07)$ & $14(2)$ & $12(2)$ & 87,871 & 2-DE & Defence/Immunity \\
\hline 24 & Plasminogen (gi|594,054,121, BB) & $290(0.21)$ & $53(9)$ & $25(6)$ & 94,095 & 2-DE & APP \\
\hline \multirow[t]{4}{*}{25} & Endopin 1b (Serpin A3-3) & $309(0.38)$ & $19(7)$ & $11(5)$ & 46,738 & 2-DE & Defence/Immunity \\
\hline & (gi| $594,074,015, \mathrm{BB})$ & $193(0.35)$ & $17(4)$ & $10(4)$ & 40,453 & & Defence/Immunity \\
\hline & Serpin A3-2 (gi|594,050,458, BB) & $50(0.09)$ & $8(3)$ & $6(3)$ & 101,449 & & APP \\
\hline & ITIH4 (gi|75,832,116, BT) & & & & & & \\
\hline 26 & Ig M heavy chain (gi| $28,592,070, \mathrm{BT})$ & $154(0.13)$ & $10(4)$ & $4(2)$ & 49,551 & 2-DE & Defence/Immunity \\
\hline 27 & $\alpha$-1B-Glycoprotein(gi|594,087,719, BB) & $439(0.48)$ & 47 (13) & $16(7)$ & 54,191 & 2-DE & $\begin{array}{l}\text { Platelet activation, signaling and } \\
\text { aggregation }\end{array}$ \\
\hline 28 & Serum Albumin (gi|594,045,062, BB) & $2706(3.07)$ & $262(89)$ & $45(31)$ & 71,177 & 2-DE & APP \\
\hline 29 & Serotransferrin (gi|594,054,424, BB) & $1181(0.90)$ & $111(37)$ & $32(16)$ & 79,994 & 2-DE & APP \\
\hline 30 & Serotransferrin (gi|594,054,424, BB) & $2325(1.78)$ & $202(69)$ & $37(25)$ & 79,994 & 2-DE & APP \\
\hline \multirow[t]{3}{*}{31} & $\alpha$-2-HS-glycoprotein (gi| $594,069,561$, & $545(0.68)$ & $56(13)$ & $11(6)$ & 38,984 & 2-DE & APP \\
\hline & $\mathrm{BB})$ & $99(0.07)$ & $6(2)$ & $5(1)$ & 49,230 & & Defence/Immunity \\
\hline & Kininogen-2 (gi|594,069,551, BB) & & & & & & \\
\hline \multirow[t]{3}{*}{32} & $\alpha 1$-antitrypsin (Serpine A1) & $938(1.18)$ & $69(31)$ & $14(11)$ & 46,290 & 2-DE & APP \\
\hline & (gi|594,050,476, BB) & $248(0.12)$ & $25(5)$ & $13(2)$ & 54,986 & & APP \\
\hline & $\begin{array}{l}\text { Vitamin D-binding protein } \\
\text { (gi| } 594,092,100, \mathrm{BB} \text { ) }\end{array}$ & & & & & & \\
\hline 33 & Hemopexin (gi|594,034,957, BB) & $69(0.07)$ & $20(1)$ & $10(1)$ & 52,691 & 2-DE & APP \\
\hline 34 & $\begin{array}{l}\text { Ig heavy chain variable region } \\
\text { (gi|1,293,600, BT) }\end{array}$ & $90(0.26)$ & $1(1)$ & $1(1)$ & 12,626 & 2-DE & Defence/Immunity \\
\hline 35 & $\begin{array}{l}\text { Ig heavy chain variable region } \\
\text { (gi } \mid 1,293,600, \mathrm{BT} \text { ) }\end{array}$ & $90(0.26)$ & $1(1)$ & $1(1)$ & 12,626 & 2-DE & Defence/Immunity \\
\hline 36 & Gelsolin isoform b (gi|77,736,201, BT) & $436(0.30)$ & $25(12)$ & $11(7)$ & 80,681 & 2-DE & Defence/Immunity \\
\hline 37 & Apolipoprotein A-I (gi| $\mid 594,065,921, \mathrm{BB})$ & 599 (1.97) & $46(21)$ & $15(11)$ & 30,232 & 2-DE & APP \\
\hline
\end{tabular}


Table 2 (continued)

\begin{tabular}{|c|c|c|c|c|c|c|c|}
\hline $\begin{array}{l}\text { Band/spot } \\
\text { number }\end{array}$ & $\begin{array}{l}\text { Protein identification (Accession } \\
\text { number, organism) }\end{array}$ & $\begin{array}{l}\text { Protein MASCOT SC } \\
\text { ore }^{\mathrm{a}}\end{array}$ & Matches $^{\mathrm{b}}$ & Sequences ${ }^{c}$ & $\begin{array}{l}\text { Estimated MW } \\
\text { (Da) }\end{array}$ & ID Method & Protein function \\
\hline 38 & Haptoglobin (gi|595,763,483, BB) & $480(0.30)$ & $35(13)$ & $7(4)$ & 45,676 & 2-DE & APP \\
\hline 39 & Haptoglobin (gi|595,763,483, BB) & $1043(1.21)$ & $116(30)$ & $21(12)$ & 45,676 & 2-DE & APP \\
\hline 40 & Haptoglobin (gi| $595,763,483, \mathrm{BB})$ & 1142 (1.07) & $138(43)$ & $21(11)$ & 45,676 & 2-DE & APP \\
\hline 41 & Ig light chain (gi| $\mid 92,096,965, \mathrm{BT})$ & $164(0.27)$ & $18(3)$ & $4(2)$ & 24,863 & 2-DE & Defence/Immunity \\
\hline 42 & Ig light chain (gi $\mid 92,096,965, \mathrm{BT})$ & $147(0.27)$ & $24(4)$ & $4(2)$ & 24,863 & 2-DE & Defence/Immunity \\
\hline 43 & Ig light chain (gi $\mid 92,096,965, \mathrm{BT})$ & $139(0.27)$ & $20(3)$ & $4(2)$ & 24,863 & 2-DE & Defence/Immunity \\
\hline 44 & Apolipoprotein A-I (gi|594,065,921, BB) & $466(1.21)$ & $50(13)$ & $15(18)$ & 30,232 & 2-DE & APP \\
\hline 45 & Haptoglobin (gi $\mid 595,763,483, \mathrm{BB})$ & $449(0.30)$ & $32(13)$ & $8(4)$ & 45,676 & 2-DE & APP \\
\hline 46 & Adiponectin (gi| $\mid 114,158,576, \mathrm{BT})$ & $28(0.00)$ & $1(0)$ & $1(0)$ & 26,117 & 2-DE & Hormone, Inflamation process \\
\hline 47 & Haptoglobin (gi|595,763,483, BB) & $1185(1.26)$ & $118(32)$ & $23(11)$ & 45,676 & 2-DE & APP \\
\hline 48 & Haptoglobin (gi|595,763,483, BB) & $560(0.94)$ & $70(17)$ & $18(10)$ & 45,676 & 2-DE & APP \\
\hline 49 & Complement C3 (gi| $594,041,230, \mathrm{BB})$ & $132(0.07)$ & $9(4)$ & $7(4)$ & 188,843 & 2-DE & APP \\
\hline 50 & $\begin{array}{l}\text { Apolipoprotein A-IV (gi|594,065,917, } \\
\text { BB) }\end{array}$ & $885(1.66)$ & $94(35)$ & $26(14)$ & 46,181 & 2-DE & Lipid metabolism \\
\hline 51 & $\begin{array}{l}\text { Antithrombin-III (Serpin C1) } \\
\text { (gi|77,736,341, BT) }\end{array}$ & $766(1.00)$ & $40(25)$ & $15(12)$ & 52,315 & 2-DE & APP \\
\hline 52 & Complement C3 (gi|594,041,230, BB) & $255(0.08)$ & $36(7)$ & $15(5)$ & 188,843 & 2-DE & APP \\
\hline 53 & Complement C3 (gi|83,764,016, BT) & $28(0.00)$ & $4(0)$ & $3(0)$ & 187,175 & 2-DE & APP \\
\hline 54 & Hemoglobin (gi|594,075,744, BB) & $930(2.27)$ & $61(29)$ & $13(10)$ & 25,066 & 2-DE & Transport \\
\hline 55 & $\begin{array}{l}\text { Serum amyloid A-4 protein } \\
\text { (gi| } \mid 94,966,809, \mathrm{BT} \text { ) }\end{array}$ & $105(0.81)$ & $6(3)$ & $3(3)$ & 14,678 & 2-DE & APP \\
\hline 56 & Serum amyloid A, SAA (gi $\mid 245,184$, BT) & $48(0.87)$ & $2(2)$ & $2(2)$ & 12,467 & 2-DE & APP \\
\hline 57 & $\begin{array}{l}\text { Glial fibrillary acidic protein } \\
\text { (gi| } 586,992,699, \mathrm{BB})\end{array}$ & $85(0.06)$ & $3(1)$ & $2(1)$ & 44,654 & 2-DE & Glycoprotein binding \\
\hline
\end{tabular}

BB, Bubalus bubalis; BT, Bos taurus; CEH, Cervus elaphus hispanicus; Ig, Immunoglobulin; APP, Acute Phase Protein; PSBF, Protein synthesis/binding/folding.

a The number in parenthesis indicates the Exponentially Modified Protein Abundance Index (emPAI).

b Total number of peptide matches. The number in parenthesis indicates the number of matches above the significance threshold ( $\mathrm{p}<0.05$ ).

c Total number of distinct peptide sequences. The number in parenthesis indicates the number of matches above the significance threshold ( $\mathrm{p}<0.05$ ).

pellet allowed to air dry by exposing to air for not $>5 \mathrm{~min}$. Subsequently the pellet was re-suspended in rehydration/sample buffer (7 M urea, 2 M thiourea, 1\% ASB-14, $40 \mathrm{mM}$ Tris, 0.001\% Bromophenol Blue) (Bio-Rad ReadyPrepTM rehydration/sample buffer).

Blood serum samples were obtained by centrifugation $\left(10 \mathrm{~min}, 4^{\circ} \mathrm{C}\right.$, $1000 \times g$ ) of $10 \mathrm{ml}$ of blood collected in siliconized vials without anticoagulant. Blood serum samples were then submitted to acetone precipitation to remove salts, using the same procedure as for the milk whey. After salts were removed, samples were also re-suspended in rehydration/sample buffer (Bio-Rad ReadyPrepTM rehydration/sample buffer).

\section{3. $1-D E$}

1-DE was performed at the Acute Phase Laboratory, Institute of Biodiversity, Animal Health \& Comparative Medicine, Garscube Campus, University of Glasgow, UK. As described (item 2.2), 10 individual patterns, from milk whey samples, and nine individual patterns, from blood serum samples, were generated.

After re-suspending the pellet in rehydration/sample buffer (BioRad ReadyPrepTM rehydration/sample buffer), total protein concentration was determined by the Bradford method (Sigma-Aldrich) so that equal protein loading of $10 \mu \mathrm{g}$ were used, in all samples, for 1-DE protein separation. Therefore, equal volumes of sample (containing $10 \mu \mathrm{g}$ of protein) and preparation solution were mixed. The preparation solution was composed of 95\% Laemmli sample buffer (Bio Rad Ltd., Hemel Hempstead, UK) + 5\% 2-mercaptoethanol (Bio Rad).

The final solution was heated in thermal block at $95^{\circ} \mathrm{C}$ for $4 \mathrm{~min}$. Meanwhile, SDS-PAGE gel (4-15\% Criterion $^{\mathrm{TM}} \mathrm{TGX}^{\mathrm{TM}}$ Precast polyacrylamide Gel, $13.3 \times 8.7 \mathrm{~cm}, 18$ wells, Bio Rad) was assembled in the gel running tank (Bio Rad, Criterion ${ }^{\mathrm{TM}}$ Vertical Electrophoresis Cell) containing running buffer (Bio Rad, $25 \mathrm{mM}$ Tris, $192 \mathrm{mM}$ glycine, $0.1 \%$ SDS, $\mathrm{pH}$ 8.3). After samples were heated, they were transferred to the SDS-PAGE gel that was previously assembled in the gel running tank as described. $10 \mu \mathrm{l}$ of pre-stained protein ladder $(10-170 \mathrm{kDa}$, PageRuler prestained protein ladder, Thermo Scientific Inc., USA) was also added into the first well.

Electrophoresis was run at $300 \mathrm{~V}$ for $15-20 \mathrm{~min}$ at room temperature. Gels were removed from the gel cassette and then stained for $1-2 \mathrm{~h}$ in colloidal solution of Coomassie brilliant blue stain G-250 dye $0.1 \%$ $(\mathrm{w} / \mathrm{v}), 10 \%(\mathrm{v} / \mathrm{v})$ acetic acid, $40 \%(\mathrm{v} / \mathrm{v})$ ethanol (Invitrogen, Manchester, UK) after which stain solution was discarded and destaining carried out overnight using a solution of $10 \%(\mathrm{v} / \mathrm{v})$ acetic acid and $25 \%(\mathrm{v} / \mathrm{v})$ methanol. Images of the gels were scanned using a UMAX Power Look III scanner and software (Hamrick software, USA).

Molecular weight (MW) and concentration of protein fractions were then determined by use of computer-assisted densitometry (CS-9301PC, Shimadzu Corporation). For the densitometric evaluation of the protein bands, reference curves were created from the wide range standard marker (MW from 6.500 to 200.000 Da, Sigma-Aldrich S8445) reading, which generated computer graphics that allowed analyses of MW and concentrations of proteins of interest, that were calculated based on total milk whey protein previously measured.

To identify protein bands that were differentially expressed during subclinical mastitis, average concentrations between $\mathrm{G} 1(\mathrm{n}=5)$ and G2 $(\mathrm{n}=5)$ were compared by unpaired $t$-test $(\mathrm{p}<0.05)$ using GraphPad Prisma 5. To identify protein bands that were differentially expressed during S. Dublin infection, average concentrations between before inoculation $(\mathrm{n}=3)$ and $72 \mathrm{~h}$ after inoculation $(\mathrm{n}=3)$ were also compared by unpaired $t$-test $(\mathrm{p}<0.05)$ using GraphPad Prisma 5.

\section{4. $2-D E$}

2-DE was performed at the Acute Phase Laboratory, Institute of Biodiversity, Animal Health \& Comparative Medicine, Garscube Campus, University of Glasgow, UK. As described (item 2.2), 10 individual gels, from milk whey samples, and nine individual gels, from blood serum samples, where generated.

After re-suspending the pellet in rehydration/sample buffer (BioRad ReadyPrepTM rehydration/sample buffer) following acetone precipitation, total protein concentration was determined by the Bradford method (Sigma-Aldrich) so that equal protein loading of $200 \mu \mathrm{g}$ were 
Table 3

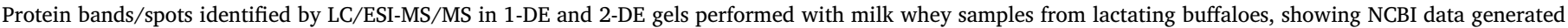
using mascot engine search.

\begin{tabular}{|c|c|c|c|c|c|c|c|}
\hline $\begin{array}{l}\text { Band/spot } \\
\text { number }\end{array}$ & $\begin{array}{l}\text { Protein identification (Accession number, } \\
\text { organism) }\end{array}$ & $\begin{array}{l}\text { Protein MASCOT } \\
\text { Score }^{\mathrm{a}}\end{array}$ & Matches $^{\mathrm{b}}$ & Sequences ${ }^{c}$ & $\begin{array}{l}\text { Estimated MW } \\
\text { (Da) }\end{array}$ & ID Method & Protein function \\
\hline \multirow[t]{2}{*}{58} & Thrombospodin-1 (gi|594,100,043, BB) & $105(0.02)$ & $11(1)$ & $10(1)$ & 133,342 & \multirow[t]{2}{*}{$1 \mathrm{D}$} & Defence/Immunity \\
\hline & a2-macroglobulin (gi| $594,093,035, \mathrm{BB})$ & $52(0.02)$ & $7(1)$ & $6(1)$ & 165,702 & & APP \\
\hline 59 & $\begin{array}{l}\text { Xanthine dehydrogenase/oxidase } \\
\text { (gi| } 594,049,883, \mathrm{BB})\end{array}$ & $231(0.08)$ & $50(5)$ & $26(4)$ & 149,733 & $1 \mathrm{D}$ & Defence/Immunity \\
\hline 60 & Ceruloplasmin (gi|296,491,101, BT) & $30(0.0)$ & $4(0)$ & $4(0)$ & 121,901 & 1D & APP \\
\hline \multirow[t]{2}{*}{61} & Complement factor B (gi $\mid 594,034,465, \mathrm{BB})$ & $264(0.32)$ & $23(9)$ & $14(8)$ & 86,804 & \multirow[t]{2}{*}{$1 \mathrm{D}$} & Defence/Immunity \\
\hline & ITIH4 (gi|594,051,965, BB) & $58(0.03)$ & $3(1)$ & $3(1)$ & 100,794 & & APP \\
\hline 62 & Gelsolin isoform b (gi|77,736,201, BT) & $50(0.08)$ & $11(2)$ & $10(2)$ & 80,966 & 1D & Defence/Immunity \\
\hline \multirow[t]{2}{*}{63} & Lactoferrin (gi|504, BT) & $507(0.60)$ & $27(16)$ & $18(12)$ & 77,129 & \multirow[t]{2}{*}{$1 \mathrm{D}$} & APP \\
\hline & Lactoperoxidase (gi|27,806,851, BT) & $82(0.08)$ & $10(3)$ & $8(2)$ & 81,504 & & Defence/Immunity \\
\hline \multirow[t]{5}{*}{64} & Lactoferrin (gi|157,830,336, BB) & $1384(1.27)$ & $116(45)$ & $34(21)$ & 77,658 & \multirow[t]{5}{*}{$1 \mathrm{D}$} & APP \\
\hline & Lactoperoxidase (gi|27,806,851, BT) & $118(0.25)$ & $12(6)$ & $9(6)$ & 81,504 & & Defence/Immunity \\
\hline & IgM heavy chain constant region & $86(0.20)$ & $4(3)$ & $3(3)$ & 48,512 & & Defence/Immunity \\
\hline & (gi $\mid 2,232,299, \mathrm{BT})$ & $74(0.04)$ & $6(2)$ & $3(1)$ & 79,870 & & APP \\
\hline & Serotransferrin (gi| $2,501,351, \mathrm{BT})$ & & & & & & \\
\hline 65 & Complement C3 (gi|594,041,230, BB) & $685(0.23)$ & 68(19) & $34(13)$ & 188,843 & 1D & APP \\
\hline \multirow[t]{2}{*}{66} & Serum Albumin (gi|594,045,062, BB) & 1335 (1.07) & $150(45)$ & 40 (17) & 71,177 & \multirow[t]{2}{*}{$1 \mathrm{D}$} & APP \\
\hline & Complement C3 (gi| $594,041,230, \mathrm{BB})$ & $200(0.10)$ & $24(6)$ & $19(6)$ & 188,843 & & APP \\
\hline \multirow[t]{4}{*}{67} & $\alpha 1$-antitrypsin (Serpin A1) (gi| $27,806,941$, & $104(0.22)$ & $8(3)$ & $5(3)$ & 46,417 & \multirow[t]{4}{*}{$1 \mathrm{D}$} & APP \\
\hline & BT) & $54(0.08)$ & $1(1)$ & $1(1)$ & 38,984 & & APP \\
\hline & $\alpha$-2-HS-glycoprotein (gi|594,069,561, BB) & $43(0.0)$ & $2(0)$ & $2(0)$ & 53,984 & & APP \\
\hline & $\begin{array}{l}\text { Lipopolysaccharide-binding protein } \\
\text { (gi| } 597,436,968, \mathrm{BB} \text { ) }\end{array}$ & & & & & & \\
\hline \multirow[t]{3}{*}{68} & Ig gamma heavy chain constant region & $88(0.42)$ & $7(1)$ & $1(1)$ & 8025 & \multirow[t]{3}{*}{$1 \mathrm{D}$} & Defence/Immunity \\
\hline & (gi|126,542,085, CEH) & $66(0.06)$ & $3(2)$ & $2(1)$ & 54,986 & & APP \\
\hline & $\begin{array}{l}\text { Vitamin D-Binding Protein } \\
\text { (gi| } 594,092,100, \text { BB) }\end{array}$ & & & & & & \\
\hline \multirow[t]{5}{*}{69} & Angiotensinogen (gi| $594,083,017, \mathrm{BB})$ & $491(0.60)$ & 37 (17) & $14(8)$ & 51,632 & $1 \mathrm{D}$ & Blood pressure, body fluid and \\
\hline & Lactadherin (gi $\mid 41,386,719, \mathrm{BT})$ & $98(0.30)$ & $7(5)$ & $6(4)$ & 48,611 & & electrolyte homeostasis \\
\hline & Endopin 2B (Serpin A3-7) (gi|38,683,423, & $61(0.07)$ & $2(1)$ & $1(1)$ & 47,200 & & Signaling, FTM \\
\hline & $\mathrm{BT})$ & $43(0.08)$ & $2(1)$ & $2(1)$ & 40,269 & & Defence/Immunity \\
\hline & $\begin{array}{l}\text { Monocyte differentiation antigen CD14 } \\
\text { (gi| } 3,913,217, \mathrm{BT} \text { ) }\end{array}$ & & & & & & Defence/Immunity \\
\hline 70 & Lactadherin (gi| $595,763,163, \mathrm{BB})$ & $186(0.30)$ & $18(6)$ & $9(4)$ & 49,015 & 1D & Signaling, FTM \\
\hline 71 & Actin, beta (gi|148,744,172, BT) & $149(0.24)$ & $15(5)$ & $7(3)$ & 42,022 & $1 \mathrm{D}$ & Development, Structural \\
\hline & Complement C3 (gi $\mid 99,028,969, \mathrm{BT}$ ) & $133(0.08)$ & $20(5)$ & $12(5)$ & 188,652 & & APP \\
\hline 72 & $\begin{array}{l}\text { Chitinase 3-like protein } 1 \text { (gi| } \mid 595,763,132 \text {, } \\
\text { BB) }\end{array}$ & $103(0.07)$ & $14(1)$ & $8(1)$ & 43,250 & $1 \mathrm{D}$ & Defence/Immunity \\
\hline 73 & Haptoglobin (gi|94,966,763, BT) & $99(0.22)$ & $16(4)$ & $6(3)$ & 45,629 & $1 \mathrm{D}$ & APP \\
\hline & Apolipoprotein A-IV (gi|594,065,917, BB) & $55(0.07)$ & $1(1)$ & $1(1)$ & 42,823 & & Lipid metabolism \\
\hline 74 & Clusterin (gi $\mid 594,072,990, \mathrm{BB})$ & $109(0.12)$ & $7(3)$ & $5(2)$ & 51,592 & $1 \mathrm{D}$ & HSP, Extracellular Chaperone \\
\hline 75 & Nucleobindin-1 (gi|115,497,814, BT) & $68(0.18)$ & $6(3)$ & $5(3)$ & 54,949 & $1 \mathrm{D}$ & Defence/Immunity \\
\hline 76 & $\begin{array}{l}\text { Ig light chain, lambda gene cluster } \\
\text { (gi| } 92,096,965, \mathrm{BB} \text { ) }\end{array}$ & $201(0.31)$ & $14(3)$ & $5(2)$ & 24,863 & $1 \mathrm{D}$ & Defence/Immunity \\
\hline 77 & Haptoglobin (gi $\mid 283,467,275, \mathrm{BB})$ & $104(0.13)$ & $6(2)$ & $3(2)$ & 48,259 & $1 \mathrm{D}$ & APP \\
\hline 78 & Apolipoprotein A-I (gi| $594,065,921, \mathrm{BB})$ & $94(0.10)$ & $5(2)$ & $4(1)$ & 30,232 & $1 \mathrm{D}$ & APP \\
\hline & Ig J Chain (gi|594,092,037, BB) & $71(0.17)$ & $6(1)$ & $3(1)$ & 18,343 & & Defence/Immunity \\
\hline 79 & $\beta$ - Lactoglobulin (gi $\mid 6,729,725, \mathrm{BT}$ ) & $1294(4.72)$ & $86(46)$ & $17(10)$ & 18,555 & $1 \mathrm{D}$ & Transport, Protein metabolism \\
\hline 80 & $\alpha$ - Lactalbumin (gi $\mid 68, \mathrm{BT})$ & $884(1.70)$ & $30(21)$ & $5(4)$ & 14,603 & $1 \mathrm{D}$ & $\begin{array}{l}\text { Carbohydrate metabolism, Lactose } \\
\text { Biosynthesis process }\end{array}$ \\
\hline 81 & Gelsolin isoform b (gi|77,736,201, BT) & $43(0.04)$ & $3(1)$ & $3(1)$ & 80,966 & $2 \mathrm{D}$ & Defence/Immunity \\
\hline 82 & $\begin{array}{l}\text { Ig M heavy chain constant region } \\
\text { (gi } \mid 28,592,070, \mathrm{BT} \text { ) }\end{array}$ & $144(0.13)$ & $5(2)$ & $5(2)$ & 50,235 & $2 \mathrm{D}$ & Defence/Immunity \\
\hline 83 & Lactoferrin (O77698, BB) & $219(0.26)$ & $20(8)$ & $13(6)$ & 79,733 & $2 \mathrm{D}$ & APP \\
\hline 84 & Lactoferrin (O77698, BB) & $408(0.21)$ & $20(9)$ & $14(5)$ & 79,733 & $2 \mathrm{D}$ & APP \\
\hline & $\begin{array}{l}\text { Ig M heavy chain constant region } \\
\text { (gi } 2,232,299, \mathrm{BT} \text { ) }\end{array}$ & $68(0.06)$ & $3(2)$ & $2(1)$ & 48,512 & & Defence/Immunity \\
\hline 85 & Serotransferrin (Q29443, BT) & $188(0.21)$ & $12(6)$ & $8(5)$ & 79,870 & $2 \mathrm{D}$ & APP \\
\hline 86 & Serotransferrin (Q29443, BT) & $423(0.36)$ & 24 (13) & $13(8)$ & 79,870 & $2 \mathrm{D}$ & APP \\
\hline & Lactoferrin (O77698, BB) & $173(0.26)$ & $18(7)$ & $13(6)$ & 79,733 & & APP \\
\hline 87 & Lactoferrin (O77698, BB) & $715(0.77)$ & $46(23)$ & $20(15)$ & 79,733 & $2 \mathrm{D}$ & APP \\
\hline & Serotransferrin (Q29443, BB) & $68(0.04)$ & $6(1)$ & $2(1)$ & 79,870 & & APP \\
\hline & Lactoperoxidase (P22079, HS) & $67(0.04)$ & $3(1)$ & $2(1)$ & 81,149 & & Defence/Immunity \\
\hline 88 & Lactoferrin (O77698, BB) & $1177(1.06)$ & $84(39)$ & 25 (19) & 79,733 & $2 \mathrm{D}$ & APP \\
\hline & Lactoperoxidase (gi| $27,806,851, \mathrm{BT}$ ) & $43(0.08)$ & $9(2)$ & $6(2)$ & 81,504 & & Defence/Immunity \\
\hline 89 & Serum Albumin (gi $\mid 1,351,907, \mathrm{BT})$ & $2116(2.28)$ & $135(79)$ & $33(28)$ & 71,244 & $2 \mathrm{D}$ & APP \\
\hline 90 & $\begin{array}{l}\text { Ig G1 heavy chain constant region } \\
\text { (gi| } 7,547,266, \mathrm{BT})\end{array}$ & $18(0.0)$ & $3(0)$ & $2(0)$ & 36,510 & $2 \mathrm{D}$ & Defence/Immunity \\
\hline 91 & Lactadherin (gi $\mid 2,494,285$, BT) & $111(0.14)$ & $2(2)$ & $2(2)$ & 48,520 & $2 \mathrm{D}$ & Signaling, FTM \\
\hline
\end{tabular}

(continued on next page) 
Table 3 (continued)

\begin{tabular}{|c|c|c|c|c|c|c|c|}
\hline $\begin{array}{l}\text { Band/spot } \\
\text { number }\end{array}$ & $\begin{array}{l}\text { Protein identification (Accession number, } \\
\text { organism) }\end{array}$ & $\begin{array}{l}\text { Protein MASCOT } \\
\text { Score }^{\mathrm{a}}\end{array}$ & Matches $^{\mathrm{b}}$ & Sequences $^{\mathrm{c}}$ & $\begin{array}{l}\text { Estimated MW } \\
\text { (Da) }\end{array}$ & ID Method & Protein function \\
\hline \multirow[t]{3}{*}{92} & Angiotensinogen (gi|166,159,174, BT) & $155(0.22)$ & $6(5)$ & $4(3)$ & 45,713 & \multirow[t]{3}{*}{$2 \mathrm{D}$} & \multirow{3}{*}{$\begin{array}{l}\text { Blood pressure, body fluid and } \\
\text { electrolyte homeostasis } \\
\text { Signaling, FTM }\end{array}$} \\
\hline & Lactadherin (gi|2,494,285, BT) & $58(0.07)$ & $5(2)$ & $4(1)$ & 48,520 & & \\
\hline & $\begin{array}{l}\text { Ig G1 heavy chain constant region } \\
\text { (gi|7,547,266, BT) }\end{array}$ & $16(0.0)$ & $4(0)$ & $1(0)$ & 36,510 & & \\
\hline \multirow[t]{5}{*}{93} & Nucleobindin-1 (gi|115,497,814, BT) & $391(0.64)$ & $30(15)$ & $13(9)$ & 54,949 & \multirow[t]{5}{*}{$2 \mathrm{D}$} & Defence/Immunity \\
\hline & Monocyte differentiation antigen CD14 & $267(0.35)$ & $13(9)$ & $5(4)$ & 40,269 & & Defence/Immunity \\
\hline & (gi| $\mid 3,913,217, \mathrm{BT})$ & $239(0.45)$ & $12(9)$ & $6(6)$ & 49,329 & & Defence/Immunity \\
\hline & Nucleobindin-2 (gi|115,496,067, BT) & $102(0.14)$ & $5(4)$ & $3(2)$ & 47,200 & & Defence/Immunity \\
\hline & $\begin{array}{l}\text { Endopin 2B (Serpin A3-7) (gi| } 38,683,423 \text {, } \\
\text { BT) }\end{array}$ & & & & & & \\
\hline \multirow[t]{6}{*}{94} & Complement C3 (gi $\mid 99,028,969$, BT) & $210(0.07)$ & $16(8)$ & $8(4)$ & 188,652 & \multirow[t]{6}{*}{$2 \mathrm{D}$} & APP \\
\hline & Cathepsin B (gi|27,806,671, BT) & $111(0.27)$ & $4(3)$ & $4(3)$ & 37,664 & & Protease, Hydrolysis of proteins \\
\hline & Actin, cytoplasmic 1 (P60712, BT) & $53(0.07)$ & $5(1)$ & $5(1)$ & 42,052 & & Development, Structural \\
\hline & Monocyte differentiation antigen CD14 & $37(0.00)$ & $3(0)$ & $1(0)$ & 40,269 & & Defence/Immunity \\
\hline & (gi| $\mid 3,913,217, \mathrm{BT})$ & $36(0.06)$ & $2(1)$ & $2(1)$ & 49,329 & & Defence/Immunity \\
\hline & Nucleobindin-2 (gi|115,496,067, BT) & & & & & & \\
\hline \multirow[t]{4}{*}{95} & Actin, beta (gi|168,177,284, BT) & $114(0.15)$ & $3(3)$ & $2(2)$ & 41,921 & \multirow[t]{4}{*}{$2 \mathrm{D}$} & Development, Structural \\
\hline & Monocyte differentiation antigen CD14 & $101(0.31)$ & $2(2)$ & $1(1)$ & 40,269 & & Defence/Immunity \\
\hline & (gi| $\mid 3,913,217, \mathrm{BT})$ & $98(0.03)$ & $5(3)$ & $3(2)$ & 188,675 & & APP \\
\hline & Complement C3 (gi $\mid 99,028,969$, BT) & & & & & & \\
\hline 96 & Complement C4 (gi $\mid 31,563,307, \mathrm{BT})$ & $36(0.11)$ & $4(1)$ & $1(1)$ & NA & $2 \mathrm{D}$ & Defence/Immunity \\
\hline 97 & Clusterin (gi|27,806,907, BT) & $401(0.51)$ & $25(15)$ & $10(7)$ & 51,651 & $2 \mathrm{D}$ & HSP, Extracellular Chaperone \\
\hline 98 & Clusterin (gi| $27,806,907, \mathrm{BT})$ & $263(0.42)$ & $16(11)$ & $17(6)$ & 51,651 & $2 \mathrm{D}$ & HSP, Extracellular Chaperone \\
\hline 99 & $\alpha$ - enolase (gi $\mid 4,927,286, \mathrm{BT})$ & $20(0.00)$ & $1(0)$ & $1(0)$ & 47,586 & $2 \mathrm{D}$ & Enzyme, Carbohydrate metabolism \\
\hline 100 & Nucleobindin-1 (gi|115,497,814, BT) & $81(0.18)$ & $6(4)$ & $4(3)$ & 54,949 & $2 \mathrm{D}$ & Defence/Immunity \\
\hline 101 & Ig light chain (gi|92,096,965, BT) & $21(0.00)$ & $2(0)$ & $2(0)$ & 24,863 & $2 \mathrm{D}$ & Defence/Immunity \\
\hline 102 & Ig light chain (gi| $92,096,965, \mathrm{BT})$ & $88(0.13)$ & $6(2)$ & $2(1)$ & 24,863 & $2 \mathrm{D}$ & Defence/Immunity \\
\hline 103 & Ig light chain (gi $\mid 2,323,374, \mathrm{BT})$ & $68(0.65)$ & $5(3)$ & $3(2)$ & 11,560 & $2 \mathrm{D}$ & Defence/Immunity \\
\hline 104 & Ig light chain (gi| $2,323,374, \mathrm{BT})$ & $221(0.65)$ & $9(8)$ & $3(2)$ & 11,560 & $2 \mathrm{D}$ & Defence/Immunity \\
\hline 105 & Ig J chain (gi|32,401,410, BT) & $49(0.17)$ & $3(2)$ & $2(1)$ & 18,359 & $2 \mathrm{D}$ & Defence/Immunity \\
\hline 106 & Apolipoprotein A-I (P15497, BT) & $85(0.22)$ & $6(2)$ & $5(2)$ & 30,258 & $2 \mathrm{D}$ & APP \\
\hline 107 & Haptoglobin (gi|94,966,763, BT) & $54(0.07)$ & $2(1)$ & $2(1)$ & 45,629 & $2 \mathrm{D}$ & APP \\
\hline 108 & $\beta$ - Lactoglobulin (P02755, BB) & $1010(1.38)$ & $73(37)$ & $13(6)$ & 20,410 & $2 \mathrm{D}$ & Transport, Protein metabolism \\
\hline 109 & $\alpha$ - Lactalbumin (Q9TSN6, BB) & $348(0.42)$ & $14(7)$ & $2(2)$ & 16,720 & $2 \mathrm{D}$ & Carbohydrate metabolism, LB \\
\hline 110 & $\begin{array}{l}\text { Fatty acid-binding protein (gi| } 27,805,809 \text {, } \\
\text { BT) }\end{array}$ & $658(1.71)$ & $33(21)$ & $8(5)$ & 14,827 & $2 \mathrm{D}$ & FTM \\
\hline 111 & a -1B-glycoprotein (gi|114,053,019, BT) & $47(0.06)$ & $3(1)$ & $2(1)$ & 54,091 & $2 \mathrm{D}$ & $\begin{array}{l}\text { Platelet activation, signaling and } \\
\text { aggregation }\end{array}$ \\
\hline
\end{tabular}

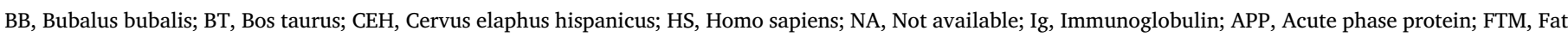
transport/metabolism; HSP, Heat shock protein; LB, Lactose biosynthesis process; PSBF, Protein synthesis/binding/folding.

a The number in parenthesis indicates the Exponentially Modified Protein Abundance Index (emPAI).

b Total number of peptide matches. The number in parenthesis indicates the number of matches above the significance threshold ( $\mathrm{p}<0.05$ ).

c Total number of distinct peptide sequences. The number in parenthesis indicates the number of matches above the significance threshold ( $\mathrm{p}<0.05$ ).

used, in all samples, for 2-DE protein separation. Therefore, final volumes of $200 \mu$ containing sample + isoelectric focusing rehydration/ sample buffer (Bio Rad, $7 \mathrm{M}$ urea, $2 \mathrm{M}$ thiourea, 1\% ASB-14, $40 \mathrm{mM}$ Tris, $0.001 \%$ Bromophenol Blue) were loaded in $11 \mathrm{~cm}$, pH 3-10 nonlinear IPG strips (BioRad, Hemel Hempstead, UK) according to manufacturer's instructions.

Rehydration and Isoelectric Focusing: The prepared samples were then applied on a gel focusing tray to a pH 3-10 non-linear IPG strip $(11 \mathrm{~cm}$, Bio-Rad Lab, UK) and covered with $1 \mathrm{ml}$ of mineral oil (SigmaAldrich, Dorset, UK). Active rehydration and then isoelectric focusing were carried out on a Bio-Rad Protean IEF cell using the following protocol: Focus temperature of $20^{\circ} \mathrm{C}$, with voltage intervals of: 1) $500 \mathrm{~V}$ for $1 \mathrm{~h}$. 2) $1000 \mathrm{~V}$ for $1 \mathrm{~h}$. 3) $2000 \mathrm{~V}$ for $2 \mathrm{~h}$. 4) $4000 \mathrm{~V}$ for $4 \mathrm{~h}$. 5) $8000 \mathrm{~V}$ for $12 \mathrm{~h}$. Focused IPG strips were then used immediately for SDS-PAGE.

SDS-PAGE (4-15\%T polyacrylamide gels): Equilibration buffer (EB) I was prepared by adding $0.5 \mathrm{~g}$ of DL dithiothreitol (DTT, SigmaAldrich) to $25 \mathrm{ml}$ of previously prepared stock buffer. EB II was prepared by adding $0.625 \mathrm{~g}$ of iodoacetamide (Sigma-Aldrich) to $25 \mathrm{ml}$ of previously prepared stock buffer. Stock buffer was prepared using $40 \mathrm{ml}$ of deionized water, $2.27 \mathrm{~g}$ of tris (Trizma base, Sigma-Aldrich) adjusted for $\mathrm{pH} 8.8,7.21 \mathrm{~g}$ of urea (Invitrogen), $10 \mathrm{ml}$ of glycerol (SigmaAldrich) applied to the solution using plastic syringe, and $1.0 \mathrm{~g}$ of sodium dodecyl sulfate (SDS, Sigma-Aldrich). These volumes were used for 8 strips. After isoelectric focusing was performed, excess of mineral oil was gently removed from the strips by using blotting paper. Focused IPG strips were then incubated for $15 \mathrm{~min}$ in EB I with gentle shaking, washed in running buffer and incubated in EB II for another $15 \mathrm{~min}$. Equilibrated IPG strips were then inserted horizontally on to the IPG well of the pre-cast IPG +1 well comb (containing the $4-15 \% \mathrm{~T}$ polyacrylamide gel) which had been previously assembled in the gel running tank (Bio Rad, Criterion ${ }^{\mathrm{TM}}$ Vertical Electrophoresis Cell) containing running buffer (Bio Rad, $25 \mathrm{mM}$ Tris, $192 \mathrm{mM}$ glycine, 0.1\% SDS, $\mathrm{pH}$ 8.3). $10 \mu \mathrm{l}$ of pre-stained protein ladder (10-170 kDa, PageRuler prestained protein ladder, Thermo Scientific Inc., USA) was added into the extra well. Electrophoresis was run at $200 \mathrm{~V}$ for $40-45 \mathrm{~min}$ at room temperature. Gels were removed from the gel cassette and then stained for 1-2 $\mathrm{h}$ in colloidal solution of Coomassie brilliant blue stain G-250 dye $0.1 \%(\mathrm{w} / \mathrm{v}), 10 \%(\mathrm{v} / \mathrm{v})$ acetic acid, $40 \%(\mathrm{v} / \mathrm{v})$ ethanol (Invitrogen, Manchester, UK) after which stain solution was discarded and destaining carried out overnight using a solution of $10 \%(\mathrm{v} / \mathrm{v})$ acetic acid and $25 \%(\mathrm{v} / \mathrm{v})$ methanol. Image of gels were scanned using a UMAX Power Look III scanner and software (Hamrick software, USA). Gel images were then processed and analyzed using SameSpot computer program (version 4.6, Totallab, UK), to highlight protein spots that showed significant and reproducible modulation between whey protein samples of interest. 

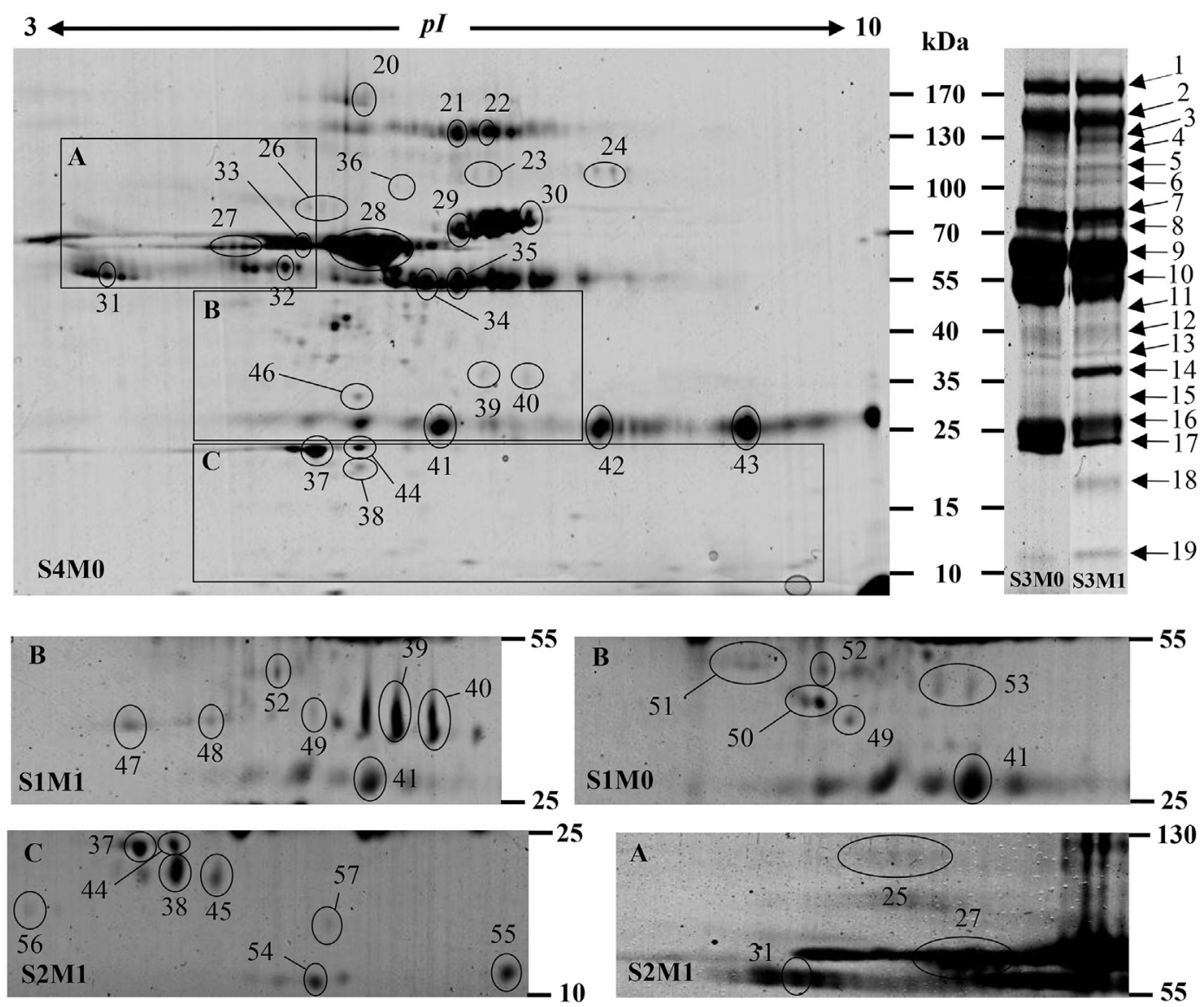

Fig. 1. Buffalo calve blood serum 1-DE reference map, represented by a healthy (S3 M0) and a S. Dublin infected (S3M1) animal, separated by SDS-PAGE (4-15\%T precast polyacrylamide gel, $13.3 \times 8.7 \mathrm{~cm}$ ) and stained with Coomassie brilliant blue, showing the identification of 19 bands (numbers 1-19). Buffalo calve blood serum 2-DE reference map, represented by healthy (S1M0, S4M0) and $S$. Dublin infected (S1M1, S2M1) animals, separated by first dimension IEF (11 cm, pH 3-10 nonlinear IPG strip) followed by second dimension SDS-PAGE (4-15\%T precast polyacrylamide gel, $13.3 \times 8.7 \mathrm{~cm}$ ) and stained with Coomassie brilliant blue, showing the identification of 38 spots (numbers 20-57). Bands and spots indicated numerically were excised and components were identified by LC/ESI-MS/MS following in-gel tryptic digestion. (For interpretation of the references to colour in this figure legend, the reader is referred to the web version of this article.)

\subsection{Trypsin digestion and LC/ESI-MS/MS}

Enzymatic digestion of proteins selected from bands and spots from 1-DE and 2-DE and LC/ESI-MS/MS were performed in the Glasgow Polyomics Facility, Garscube Campus, University of Glasgow, UK.

Tryptic peptides were generated and extracted from gel pieces as previously described (Daneshvar et al., 2012), and were analyzed by LC/ESI-MS/MS (liquid chromatography coupled with electrospray ionization tandem mass spectrometry), using a Amazon ion trap instrument to produce MS and MS/MS data (Amazon speed ETD, Bruker Daltonics). The MS data obtained was processed using Data Analysis software (Bruker) and the automated Matrix Science Mascot Daemon server (v2.1.06). Protein identification was assigned using the Mascot search engine to interrogate protein sequences in the NCBI predicted protein database (Swissprot) restricting the search to Bos taurus and mammalian sequences, allowing a precursor mass tolerance and a fragment ion mass tolerance of $0.4 \mathrm{Da}$ for both MS and MS/MS data. Also, trypsin was selected as cleavage enzyme, carbamidomethyl (C) as fixed modification and oxidation of methionine as variable modification.

\subsection{Haptoglobin concentration in blood serum of buffalo calves}

Haptoglobin concentrations were analyzed on a ABX Pentra 400 (Horiba ABX SAS, Montpellier, France) by using a hemoglobin binding method developed by Eckersall et al. (1999). Average concentrations between before inoculation (M0) $(\mathrm{n}=3)$ and $72 \mathrm{~h}$ after inoculation
(M1) $(\mathrm{n}=3)$ were compared by unpaired $t$-test $(\mathrm{p}<0.05)$ using GraphPad Prisma 5.

\section{Results and discussion}

\subsection{Reference 1-DE and 2-DE maps}

The great interest of this study was to identify potential disease related proteins, with emphasis on APP and defence/immunity related proteins, in blood serum of buffalo calves and in milk whey of lactating buffaloes, in order to define a reference electrophoresis map, both for 1$\mathrm{DE}$ and 2-DE, as a prerequisite for future investigation of protein disease patterns. In this sense, the identification of these proteins in gels can help to address alterations during diseases in further studies and therefore must be highlighted in buffalo, since little is known about the proteome of this species.

For the construction of the protein maps, blood serum samples from healthy and $S$. Dublin infected buffalo calves were used, as well as healthy and mastitic milk whey samples (Table 1). Thus, healthy and diseased animal samples were used to find and identify the highest possible number of APP and defence/immunity-related proteins and therefore construct maps as complete as possible. In this context, it is also important to address that the use of 1-DE, although limited, is always an important tool for selecting samples, from a larger pool of samples, for further analysis by higher resolution methods such us 2-DE and gel-free LC-MS analyses, and this was the reason that construct maps a both 1-DE and 2-DE maps were constructed in this study. 


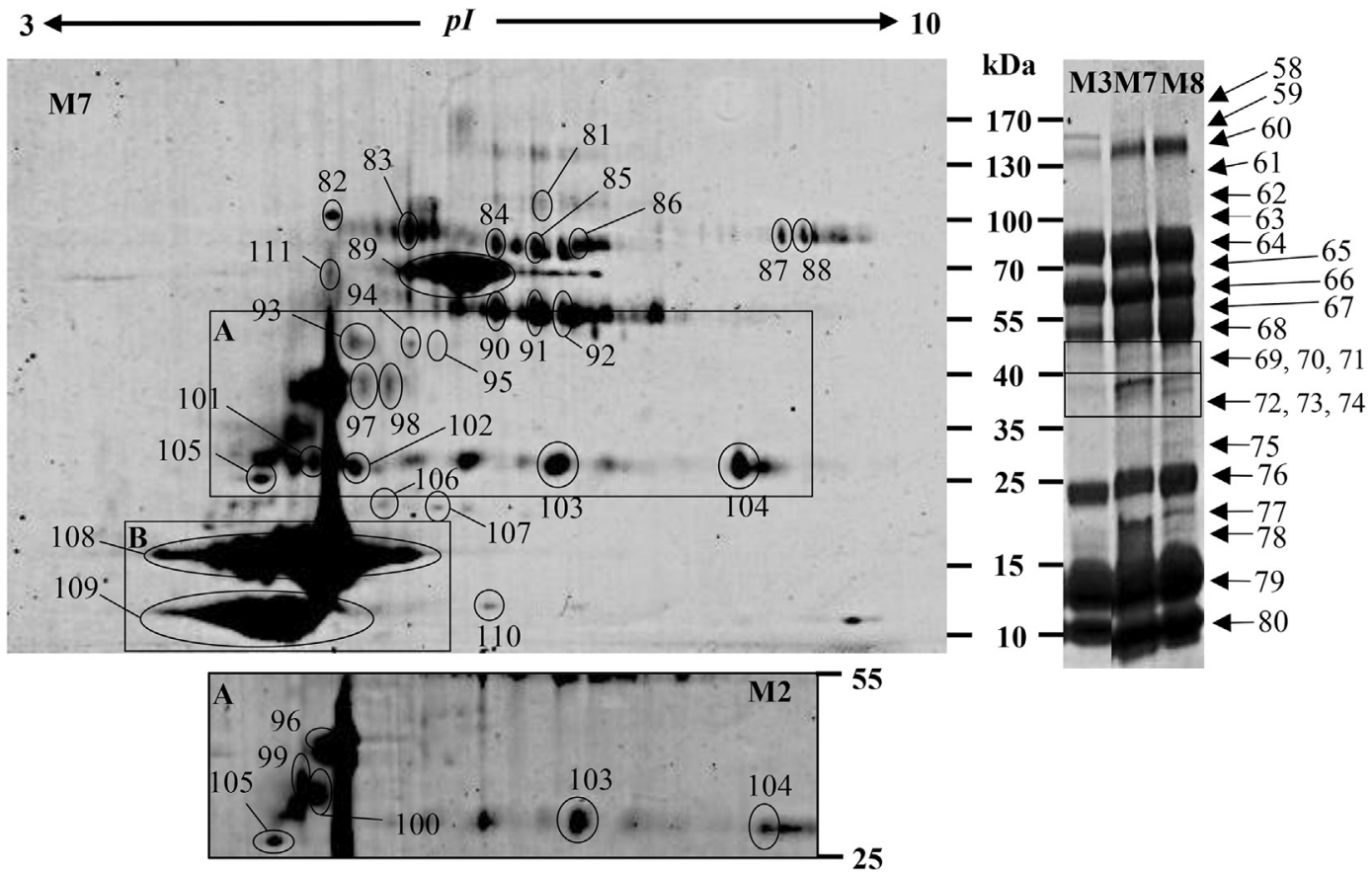

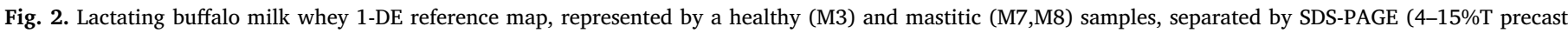

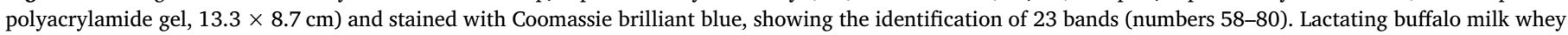

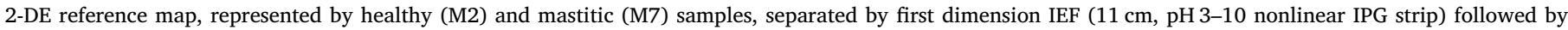

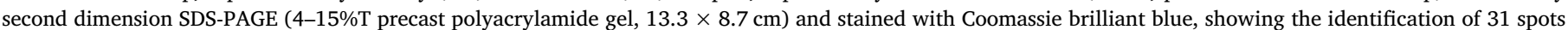

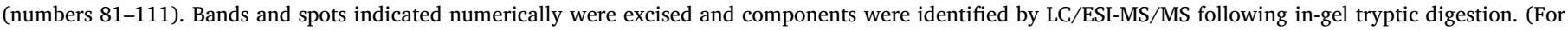
interpretation of the references to colour in this figure legend, the reader is referred to the web version of this article.)

For the construction of the 1-DE reference protein maps, a total of 19 bands from blood serum of buffalo calves and 23 bands from milk whey of lactating buffaloes were excised and analyzed by LC/ESI-MS/ MS. After interrogating the MS data obtained with bovine and mammalian sequences in the NCBI predicted protein database, 27 different proteins were identified in the blood serum of buffalo calves, while 33 different proteins were identified in the milk whey of lactating buffaloes, and proteome maps were generated (Table 2, Table 3, Fig. 1, Fig. 2). Among these proteins, 12 APP and 13 defence $\backslash$ immunity related proteins were identified in the blood serum of buffalo calves, while 13 APP and 13 defence/immunity related proteins were identified in the milk whey of lactating buffaloes (Fig. 3a and b).

For the construction of the 2-DE reference protein maps, a total of 38 spots from blood serum of buffalo calves and 31 spots from milk whey of lactating buffaloes were excised and analyzed by LC/ESI-MS/ MS, and 30 different proteins were identified in the blood serum of buffalo calves, while 28 different proteins were identified in the milk whey of lactating buffaloes, and therefore maps were generated (Table 2, Table 3, Fig. 1, Fig. 2). Among these proteins, 16 APP and 9 defence/immunity related proteins were identified in the blood serum of buffalo calves, while 6 APP and 11 defence/immunity related proteins were identified in the milk whey of lactating buffaloes (Fig. $3 \mathrm{c}$ and d).

As described, 1-DE and 2-DE allowed the identification of 27 and 30 different blood serum proteins, respectively. When comparing the two approaches, data show that 22 different proteins were identified by both techniques (Table 4, Fig. $4: 14 \mathrm{~V}$ to $35 \mathrm{~V}$ of the venn diagram), while 5 proteins where only identified by 1 -DE ( $1 \mathrm{~V}$ to $5 \mathrm{~V}$ of the venn diagram) and 8 only by $2-\mathrm{DE}$ ( $6 \mathrm{~V}$ to $13 \mathrm{~V}$ of the venn diagram). Therefore, by using a combined approach (1-DE + 2-DE), this study was able to identify 35 different blood serum proteins $(1 \mathrm{~V}$ to $35 \mathrm{~V}$ of the venn diagram). In the same way, $1-\mathrm{DE}$ and 2 -DE allowed the identification of 33 and 28 different milk whey proteins, respectively. When comparing the two approaches, data show that 21 different proteins were identified by both techniques $(55 \mathrm{~V}$ to $75 \mathrm{~V}$ of the venn diagram), while 12 proteins where only identified by $1-\mathrm{DE}$ ( $36 \mathrm{~V}$ to $47 \mathrm{~V}$ of the venn diagram) and 7 only by $2-\mathrm{DE}$ ( $48 \mathrm{~V}$ to $54 \mathrm{~V}$ of the venn diagram). Therefore, by using a combined approach (1-DE + 2-DE), this study was able to identify 40 different buffalo milk proteins $(36 \mathrm{~V}$ to $75 \mathrm{~V}$ of the venn diagram). Among these proteins, important APP, defence/immunity related proteins (immunoglobulins, complement system related proteins, serpins, apolipoproteins), and proteins with other functions were identified (Fig. 3e and f) and are discussed below in relation to these protein classes.

The MS data obtained was compared with mammalian and Bos taurus sequences in the NCBI predicted protein database. Comparing MS data with mammalian sequences allowed us to identify 24 blood serum proteins and 22 milk whey proteins from Bubalus bubalis sequences. However, among all different proteins identified combining 1-DE + 2DE (35 blood serum proteins and 40 milk whey proteins), 11 blood serum proteins and 18 milk whey proteins were not detected using Bubalus bubalis sequences in NCBI. Therefore, considering that the NCBI predicted protein database has many more Bos taurus protein sequences, we were able to identify several buffalo proteins by homology with Bos taurus sequences (Tables 2 and 3).

\subsubsection{Identification of APP in blood serum}

APP have been extensively studied in bovines for use in diagnosis, prognosis and in monitoring response to therapy, as well as in general health screening (Eckersall and Bell, 2010), and therefore is an important class of proteins to be explored in buffaloes. In this study, 16 different APP in blood serum from buffalo calves were detected by using a combined 1-DE and 2-DE approach, coupled with LC/ESI-MS/ MS (Tables 2 and 4, Figs. 3E and 4). Among these proteins, 12 positive APP (haptoglobin, ceruloplasmin, SAA, SAA4, hemopexin, complement C3, a2-macroglobulin, ITIH4, plasminogen, a2-HS-glycoprotein, apolipoprotein A1 and $\alpha 1$-antitrypsin) and 4 negative APP (antithrombin III, serotransferrin, serum albumin and vitamin D binding protein) were 

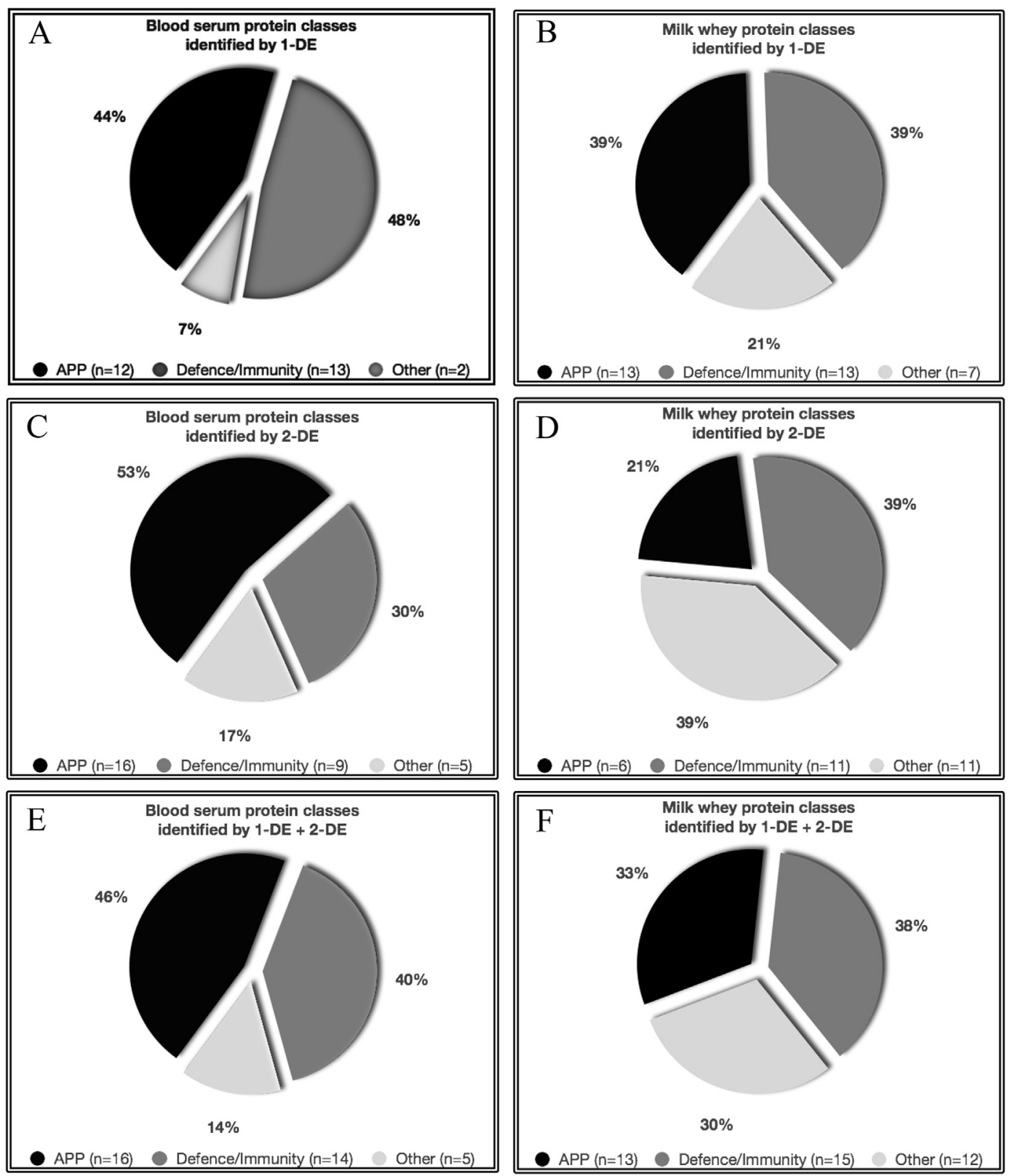

Fig. 3. Distribution into three different protein classes (APP, defence/immunity and others), of 38 proteins identified in buffalo calves blood serum 1-DE (A), of 30 proteins identified in lactating buffaloes milk whey 1-DE (B), of 30 proteins identified in buffalo calves blood serum 2-DE (C) and of 28 proteins identified in lactating buffaloes milk whey 2-DE (D). Also, distribution of 35 different proteins identified in buffalo calves blood serum considering 1-DE +2 -DE (E) and of 40 different proteins identified in lactating buffaloes milk whey considering 1-DE + 2-DE (F).

identified. All of these proteins were identified by 2-DE, while all except SAA, SAA4, hemopexin and antithrombin III were identified by 1-DE (Table 2, Figs. 3E and 4).

In relation to the proteins identified both by 1-DE and 2-DE, similar positions were observed in the gels by comparing the respective molecular weights (Fig. 1). For instance, haptoglobin was identified between 15 and $25 \mathrm{kDa}$ (band 19, spot 38) and 35-40 kDa (band 14 and spots $39,40,47,48$ ), ceruloplasmin between 130 and $170 \mathrm{kDa}$ (band 2 and spots 21, 22), complement C3 between 55 and $70 \mathrm{kDa}$ (band 12, 13 and spots 49,52, 53), $\alpha 2$-macroglobulin near $170 \mathrm{kDa}$ (band 1 and spot 20), ITIH4 near $130 \mathrm{kDa}$ (band 3 and spot 25), plasminogen between 100 and $130 \mathrm{kDa}$ (band 6 and spot 24), $\alpha 2$-HS-glycoprotein near $55 \mathrm{kDa}$ (band 10 and spot 31), apolipoprotein A1 between 15 and $25 \mathrm{kDa}$ (band 17 and spots 37, 44), $\alpha 1$-antitrypsin between 55 and $70 \mathrm{kDa}$ (band 9 and spot 32), serotransferrin between 70 and $100 \mathrm{kDa}$ (bands 7, 8 and spots 29, 30), serum albumin between 55 and $70 \mathrm{kDa}$ (band 9 and spot
28) and vitamin D binding protein near $55 \mathrm{kDa}$ (band 10 and spot 32). In relation to the APP haptoglobin, ceruloplasmin, complement C3, a2-macroglobulin, ITIH4, plasminogen, $\alpha 2$-HS-glycoprotein, apolipoprotein A1, $\alpha 1$-antitrypsin, serotransferin and serum albumin, identified by 2-DE in our study, similar molecular weights (MW) and isoelectric point (pI) were observed when comparing to other studies where 2-DE gels were performed in bovine blood serum/plasma using $7 \mathrm{~cm}$ IPG strips with pH range of 4.0-7.0 (Alonso-Fauste et al., 2012), $18 \mathrm{~cm}$ IPG strips with pH range of 3.5-10.0 (Talamo et al., 2003) and IPG strips with pH range of 4.0-10.0 (Wait et al., 2002).

Studies performed by Takahashi et al. (2009) in bovine serum samples using IPG strips with $\mathrm{pH}$ range of 3.0-10.0 identified 7 SAA isoforms ranging from pI 5.2-8.6 and MW of around $14 \mathrm{kDa}$. In our work, SAA was identified in similar position, below $15 \mathrm{kDa}$ and in $\mathrm{pI}$ near 5.0 and 9.0 . 
Table 4

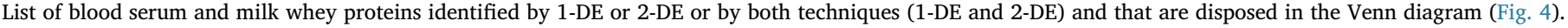

\begin{tabular}{|c|c|c|c|c|c|}
\hline ID Method & Venn diagram blood serum protein ID & Blood serum protein name & ID Method & Venn diagram milk whey protein ID & Milk whey protein name \\
\hline \multirow{6}{*}{$\begin{array}{l}1-\mathrm{DE} \\
\qquad(\mathrm{n}=5)\end{array}$} & & Defence/immunity & $1-\mathrm{DE}$ & & APP \\
\hline & $1 \mathrm{~V}$ & Complement C4-A & $(\mathrm{n}=12)$ & $36 \mathrm{~V}$ & Ceruloplasmin \\
\hline & $2 \mathrm{~V}$ & Complement C5a & & $37 \mathrm{~V}$ & ITIH4 \\
\hline & $3 \mathrm{~V}$ & Complement C6 & & $38 \mathrm{~V}$ & LBP \\
\hline & $4 \mathrm{~V}$ & Complement factor I & & $39 V$ & Vitamin D-Binding Protein \\
\hline & $5 \mathrm{~V}$ & Endopin 2B (Serpin A3-7) & & $40 \mathrm{~V}$ & $\alpha$-2-HS- glycoprotein \\
\hline \multirow{10}{*}{$\begin{array}{l}2-\mathrm{DE} \\
\qquad(\mathrm{n}=8)\end{array}$} & & APP & & $41 \mathrm{~V}$ & $\alpha 1$-antitrypsin (Serpin A1) \\
\hline & $6 \mathrm{~V}$ & Hemopexin & & $42 \mathrm{~V}$ & $\alpha 2$-macroglobulin \\
\hline & $7 \mathrm{~V}$ & Serpin C1 (Antithrombin-III) & & & Defence/Immunity \\
\hline & $8 \mathrm{~V}$ & Serum amyloid A (SAA) & & $43 \mathrm{~V}$ & Chitinase 3 -like protein 1 \\
\hline & $9 \mathrm{~V}$ & Serum amyloid A4 (SAA4) & & $44 \mathrm{~V}$ & Complement factor B \\
\hline & & Defence/immunity & & $45 \mathrm{~V}$ & Thrombospodin-1 \\
\hline & $10 \mathrm{~V}$ & $\begin{array}{l}\text { Complement factor } \mathrm{H} \\
\text { Others }\end{array}$ & & $46 \mathrm{~V}$ & $\begin{array}{l}\text { Xanthine dehydrogenase/oxidase } \\
\text { Others }\end{array}$ \\
\hline & $11 \mathrm{~V}$ & Apolipoprotein A-IV & & $47 \mathrm{~V}$ & Apolipoprotein A-IV \\
\hline & $12 \mathrm{~V}$ & GFAP & 2-DE & & Defence/immunity \\
\hline & $13 \mathrm{~V}$ & $\alpha$-1B-Glycoprotein & $(\mathrm{n}=7)$ & $48 \mathrm{~V}$ & Complement C4 \\
\hline \multirow{31}{*}{$\begin{array}{l}\text { 1-DE } \\
\quad \text { and } \\
2 \text {-DE } \\
(\mathrm{n}=22)\end{array}$} & & APP & & $49 \mathrm{~V}$ & Nucleobindin-2 \\
\hline & $14 \mathrm{~V}$ & Apolipoprotein A-I & & & Others \\
\hline & $15 \mathrm{~V}$ & Ceruloplasmin & & $50 \mathrm{~V}$ & Actin, cytoplasmic 1 \\
\hline & $16 \mathrm{~V}$ & Complement C3 & & $51 \mathrm{~V}$ & Cathepsin B \\
\hline & $17 \mathrm{~V}$ & Haptoglobin & & $52 \mathrm{~V}$ & Fatty acid-binding protein \\
\hline & $18 \mathrm{~V}$ & ITIH4 & & $53 \mathrm{~V}$ & $\alpha$ - enolase \\
\hline & $19 \mathrm{~V}$ & Plasminogen & & $54 \mathrm{~V}$ & $\alpha$-1B-glycoprotein \\
\hline & $20 \mathrm{~V}$ & Serotransferrin & 1-DE & & APP \\
\hline & $21 \mathrm{~V}$ & Serum Albumin & and & $55 \mathrm{~V}$ & Apolipoprotein A-I \\
\hline & $22 \mathrm{~V}$ & Vitamin D-binding protein & 2-DE & $56 \mathrm{~V}$ & Complement C3 \\
\hline & $23 \mathrm{~V}$ & $\alpha$-2-HS-glycoprotein & $(\mathrm{n}=21)$ & $57 \mathrm{~V}$ & Haptoglobin \\
\hline & $24 \mathrm{~V}$ & $\alpha 1$-antitrypsin (Serpine A1) & & $58 \mathrm{~V}$ & Lactoferrin \\
\hline & $25 \mathrm{~V}$ & $\alpha 2$-macroglobulin & & $59 \mathrm{~V}$ & Serotransferrin \\
\hline & & Defence/Immunity & & $60 \mathrm{~V}$ & Serum Albumin \\
\hline & $26 \mathrm{~V}$ & Complement factor B & & & Defence/Immunity \\
\hline & $27 \mathrm{~V}$ & Endopin 1b (Serpin A3-3) & & $61 \mathrm{~V}$ & $\mathrm{CD} 14$ \\
\hline & $28 \mathrm{~V}$ & Gelsolin isoform b & & $62 \mathrm{~V}$ & Endopin 2B (Serpin A3-7) \\
\hline & $29 \mathrm{~V}$ & Ig heavy chain variable region & & $63 \mathrm{~V}$ & Gelsolin isoform b \\
\hline & $30 \mathrm{~V}$ & Ig M heavy chain & & $64 \mathrm{~V}$ & Ig G1 HC constant region/ Ig HC \\
\hline & $31 \mathrm{~V}$ & Ig light chain & & $65 \mathrm{~V}$ & Ig J Chain \\
\hline & $32 \mathrm{~V}$ & Kininogen-2 & & $66 \mathrm{~V}$ & Ig light chain \\
\hline & $33 \mathrm{~V}$ & Serpin A3-2 & & $67 \mathrm{~V}$ & IgM heavy chain constant region \\
\hline & & Others & & $68 \mathrm{~V}$ & Lactoperoxidase \\
\hline & $34 \mathrm{~V}$ & Adiponectin & & $69 \mathrm{~V}$ & Nucleobindin-1 \\
\hline & $35 \mathrm{~V}$ & Hemoglobin & & & Others \\
\hline & - & - & & $70 \mathrm{~V}$ & Actin, beta \\
\hline & - & - & & $71 \mathrm{~V}$ & Angiotensinogen \\
\hline & - & - & & $72 \mathrm{~V}$ & Clusterin \\
\hline & - & - & & $73 \mathrm{~V}$ & Lactadherin \\
\hline & - & - & & $74 \mathrm{~V}$ & $\alpha$ - Lactalbumin \\
\hline & - & - & & $75 \mathrm{~V}$ & $\beta$ - Lactoglobulin \\
\hline
\end{tabular}

\subsubsection{Identification of APP in milk whey}

One of the most important applications of measuring APP in bovine medicine is in detection and monitoring of bovine mastitis, an endemic disease of dairy cows which causes major economic losses (Ceciliani et al., 2012). In buffaloes, mastitis also can cause major economic losses, and studies with alterations in APP have shown increased concentrations of haptoglobin and serum amyloid A in the milk during mastitis (Kumar et al., 2014). In this study, 13 different APP in milk whey were detected by using a combined 1-DE and 2-DE approach, coupled with LC/ESI-MS/MS (Tables 3 and 4, Figs. 3F and 4). Among these proteins, 10 positive APP (haptoglobin, lactoferrin, complement C3, ceruloplasmin, $\alpha 2$-macroglobulin, ITIH4, $\alpha 2$-HS-glycoprotein, apolipoprotein A1, $\alpha 1$-antitrypsin and lipopolysaccharide-binding protein - LBP) were identified. Also, important negative blood APP, that act as positive APP in the mammary gland during mastitis (serotransferrin and serum albumin) and negative APP (vitamin D binding protein) were identified. All of these proteins were identified by 1-DE, while six were identified by 2-DE (haptoglobin, lactoferrin, complement C3, apolipoprotein A1, serotransferrin and serum albumin).

In relation to the proteins identified both by $1-\mathrm{DE}$ and $2-\mathrm{DE}$, similar positions were observed in the gels by comparing the respective molecular weights (Fig. 2). Haptoglobin was identified between 15 and $25 \mathrm{kDa}$ (band 77, spot 107), lactoferrin between 70 and $100 \mathrm{kDa}$ (bands 63, 64 and spots 83, 84, 86, 87, 88), complement C3 between 40 and $55 \mathrm{kDa}$ (band 71 and spots 94, 95), apolipoprotein A1 between 15 and $25 \mathrm{kDa}$ (band 78 and spot 106), serotransferrin between 70 and $100 \mathrm{kDa}$ (band 64 and spots 85, 86, 87) and serum albumin between 55 and $70 \mathrm{kDa}$ (band 66 and spot 89).

Comparing our findings with studies performed with bovine milk whey (Alonso-Fauste et al., 2012; Smolenski et al., 2014), similar positions were observed in the gels for haptoglobin, identified between 15 and $25 \mathrm{kDa}$ and near pI 6.0. According to Alonso-Fauste et al. (2012), the protein identified in this position is the $\alpha$-haptoglobin fraction, since the $\beta$-haptoglobin tends to be identified between 35 and $40 \mathrm{kDa}$. In addition to haptoglobin, other important APP such as lactoferrin, complemente $\mathrm{C} 3$, apolipoprotein $\mathrm{A} 1$, serotransferrin and serum albumin have also been identified in similar positions in cattle, respectively, between 67 and $120 \mathrm{kDa}$ and pI 7.0-9.0 (Smolenski et al., 2007; Alonso-Fauste et al., 2012), 45-60 kDa and pH 6.0 (Boehmer et al., 2008; Alonso-Fauste et al., 2012), 15-31 kDa and pI 6.0 (Smolenski 


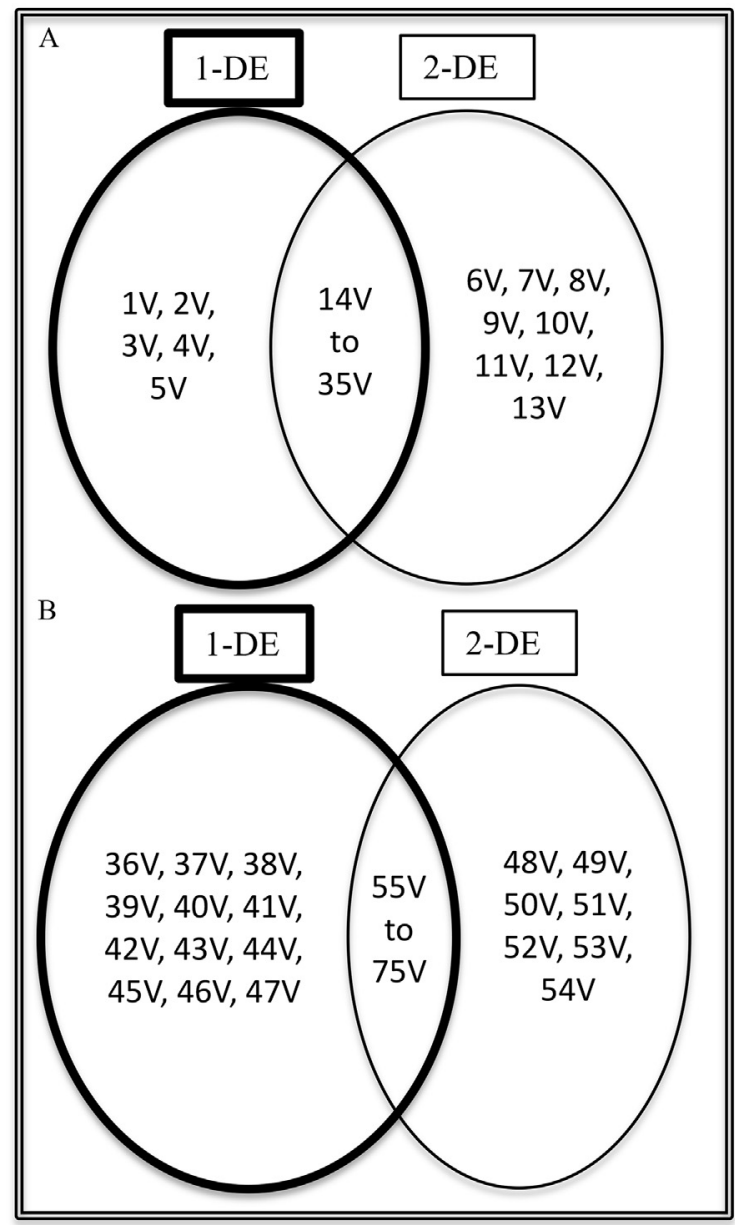

Fig. 4. Protein information from Table 4 is presented using a Venn diagram analysis. Panel A shows blood serum proteins only identified by 1-DE (left:1V to $5 \mathrm{~V}$ ) and only identified by 2-DE (right:6V to $13 \mathrm{~V}$ ), with common proteins in the center (14V to $35 \mathrm{~V}$ ). Panel B shows milk whey proteins only identified by 1-DE (left:36V to $47 \mathrm{~V}$ ) and only identified by 2-DE (right:48V to $54 \mathrm{~V}$ ), with common proteins in the center ( $55 \mathrm{~V}$ to $75 \mathrm{~V}$ ). et al., 2007; Boehmer et al., 2008; Alonso-Fauste et al., 2012), 50-75 kDa and pI 6.0-7.0 (Boehmer et al., 2008; Alonso-Fauste et al., 2012) and 70-100 kDa and pH7.0-9.0 (Smolenski et al., 2007; Boehmer et al., 2008; Alonso-Fauste et al., 2012).

\subsubsection{Identification of defence/immunity related proteins in the blood serum}

In this study, 14 blood serum defence/immunity related proteins were detected by using a combined 1-DE and 2-DE approach, coupled with LC/ESI-MS/MS, and among this class of proteins, important immunoglobulins, proteins linked to the complement system and serpins were identified (Tables 2 and 4, Figs. 3E and 4).

In the blood serum of buffalo calves, 3 immunoglobulins (Ig M Heavy Chain, Ig Heavy Chain and Ig Light Chain) were identified by performing a combined 1-DE and 2-DE approach (Tables 2 and 4, Fig. 4). The 3 immunoglobulins were identified both by 1-DE and 2-DE (Table 2, Figs. 3E and 4), and similar positions were observed in the gels by comparing the respective molecular weights (Fig. 1). For instance, Ig M Heavy Chain was identified between 70 and $100 \mathrm{kDa}$ (band 8, spot 26), Ig Heavy Chain near $55 \mathrm{kDa}$ (band 10 and spots 34, 53) and Ig Light Chain near $25 \mathrm{kDa}$ (band 16 and spots 41, 42, 43).

Although bovine and mammalian sequences in the NCBI predicted protein database did not allow us to identify Ig Heavy Chain (band 10 and spots 34, 53) and Ig Light Chain (band 16 and spots 41, 42, 43) as a specific immunoglobulin class, the position of these bands/spots in the gels, when compared to cattle (Alonso-Fauste et al., 2012) and sheep (Chiaradia et al., 2012) blood serum, gives a strong indication that these proteins are from the Ig G class. This is because in blood serum bovine 2-DE gels (7 cm IPG strips pH 4-7), Ig G1 Heavy Chain and Ig G2a Heavy Chain have been identified between 45 and $67 \mathrm{kDa}$ (AlonsoFauste et al., 2012), in very similar positions where Ig Heavy Chain was identified in our work (band 10 and spots 34 and 53, near to $55 \mathrm{kDa}$ ). Also, in blood serum sheep 2-DE gels (17 cm IPG strips pH 3-10), Ig Ga Lambda Chain has been identified near $55 \mathrm{kDa}$ (Chiaradia et al., 2012), also in very similar positions where Ig Light Chain was identified in our work (band 16 and spots 41, 42 and 43, near to $55 \mathrm{kDa}$ ). Also, Ig M Heavy Chain, identified between 70 and $100 \mathrm{kDa}$ (band 8, spot 26), has already been identified in similar position in bovine blood serum 2-DE, above and at left side of serum albumin (Wait et al., 2002) and between 67 and $120 \mathrm{kDa}$ (Alonso-Fauste et al., 2012).

Table 5

Proteins from 1-DE and 2-DE differentially expressed, comparing blood serum samples from newborn buffalo-calves before inoculation (M0) and $72 \mathrm{~h}$ after inoculation with $10^{8} \mathrm{CFU}$ of S. Dublin (M1), and comparing milk whey samples from healthy buffaloes (G1) and from buffaloes with subclinical mastitis (G2).

\begin{tabular}{|c|c|c|c|c|}
\hline \multicolumn{5}{|c|}{ Blood serum samples from buffalo calves } \\
\hline Band/spot number & Protein identification (Accession number, organism) & ID method & Anova $(\mathrm{p})^{\mathrm{a}}$ & Fold change (M1/M0) \\
\hline 14 & Haptoglobin (gi|595,763,483, BT) - $\beta$-fraction & 1-DE & 0.0451 & +19.8 \\
\hline 39 & Haptoglobin (gi| $595,763,483, \mathrm{BB})$ - $\beta$-fraction & 2-DE & 0.0007 & +6.2 \\
\hline 40 & Haptoglobin (gi $\mid 595,763,483, \mathrm{BB})$ - $\beta$-fraction & 2-DE & 0.0006 & +6.3 \\
\hline 18 & Haptoglobin (gi $\mid 283,467,275, \mathrm{BB})$ - $\alpha$-fraction & 1-DE & $<0.0001$ & +39.0 \\
\hline 38 & Haptoglobin (gi| $595,763,483, \mathrm{BB})$ - $\alpha$-fraction & 2-DE & 0.0330 & +5.4 \\
\hline 45 & Haptoglobin (gi| $595,763,483, \mathrm{BB})$ - $\alpha$-fraction & 2-DE & 0.0430 & +4.3 \\
\hline- & Haptoglobin - Total & HBM & 0.0028 & +37.5 \\
\hline \multicolumn{5}{|c|}{ Milk whey samples from lactating buffaloes } \\
\hline Band/Spot number & Protein identification (Accession number, organism) & ID method & Anova $(\mathrm{p})^{\mathrm{a}}$ & Fold change (G2/G1) \\
\hline 76 & Ig light chain, lambda gene cluster (gi $\mid 92,096,965, \mathrm{BB}$ ) & 1-DE & 0.0290 & +5.6 \\
\hline 103 & Ig light chain (gi $\mid 2,323,374, \mathrm{BT})$ & 2-DE & 0.0133 & +1.7 \\
\hline 104 & Ig light chain (gi $\mid 2,323,374, \mathrm{BT})$ & 2-DE & 0.0124 & +1.9 \\
\hline 79 & $\beta$ - Lactoglobulin (gi $\mid 6,729,725$, BT) & 1-DE & 0.0298 & -1.3 \\
\hline 108 & $\beta$ - Lactoglobulin (P02755, BB) & 2-DE & $<0.0001$ & -2.5 \\
\hline 80 & $\alpha$ - Lactalbumin (gi|68, BT) & 1-DE & 0.0118 & -1.4 \\
\hline 109 & $\alpha$ - Lactalbumin (Q9TSN6, BB) & 2-DE & 0.0002 & -3.0 \\
\hline
\end{tabular}

Ig, Immunoglobulin.

Hemoglobin Binding Method (HBM): Based on the method of Eckersall et al. (1999).

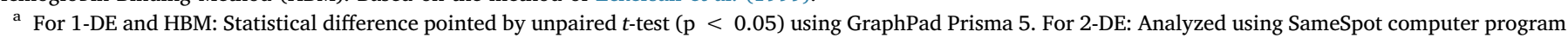
(version 4.6, Totallab, UK). 


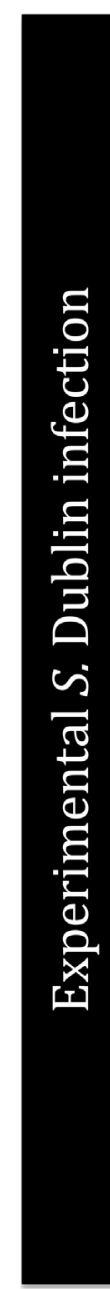

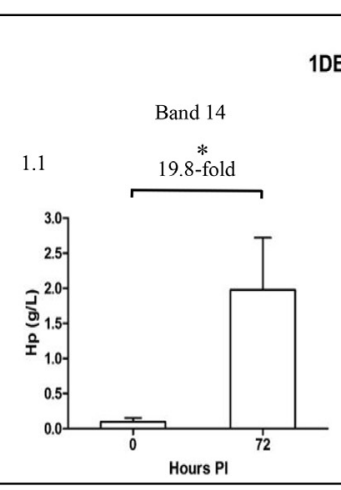

IDE Method
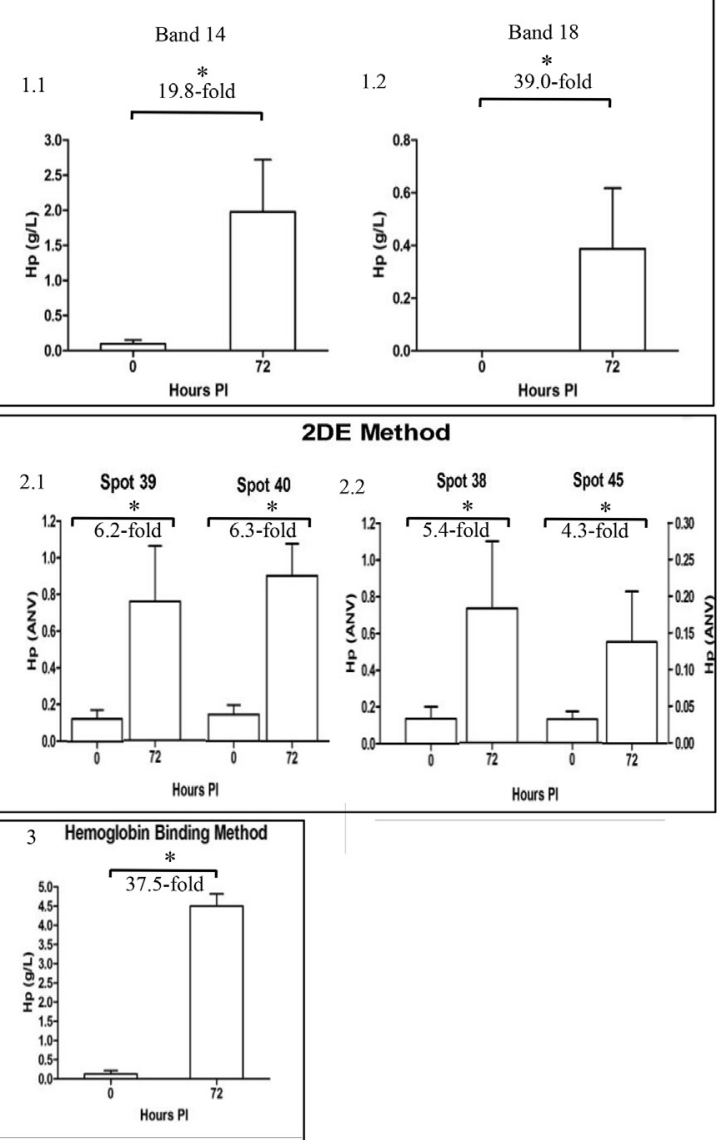
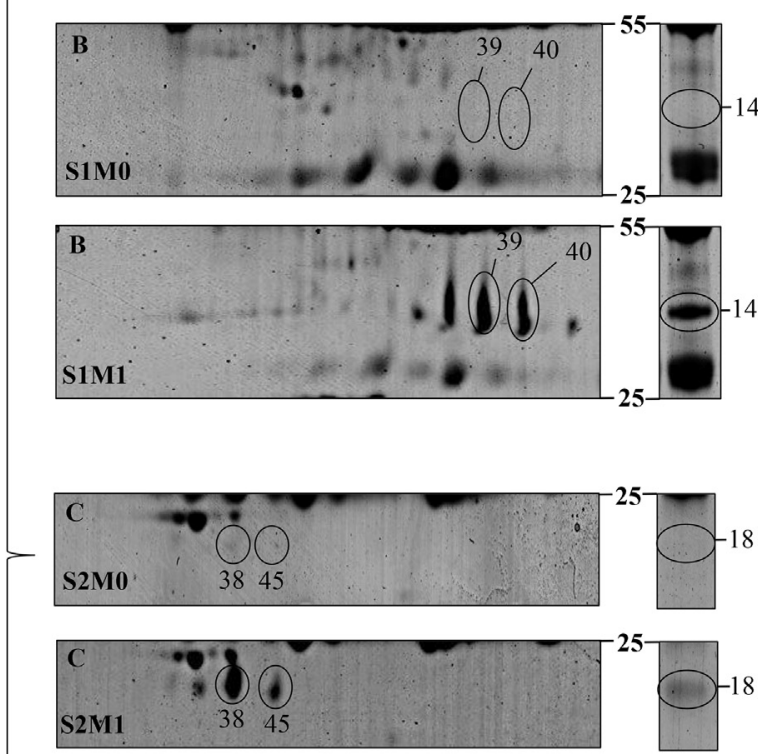

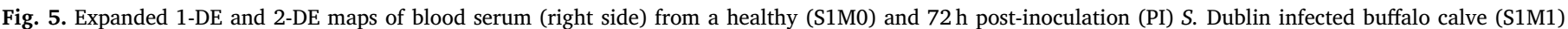

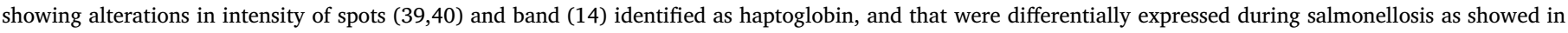

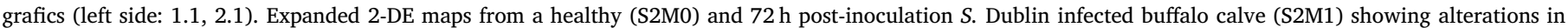

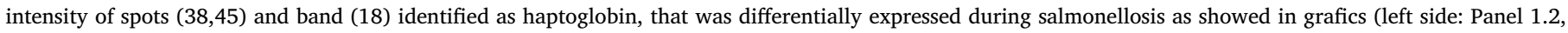

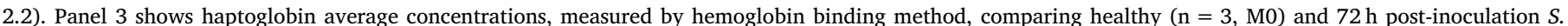

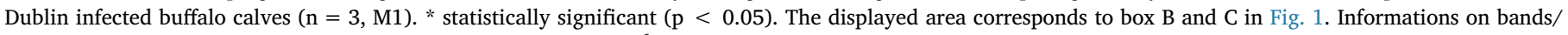
spots ID are in Table 1 . ANV $=$ Average Normalized Volume $\times 10^{6}$.

There are three pathways of complement activation, the classical, the alternative and the lectin pathways. All three pathways are activated according to a cascade system, with activation of one factor leading to the activation of the next (Ballanti et al., 2011). In this study, 7 different blood serum complement factors (C3, C4a, C5a, C6, B, H and I) were detected by using a combined 1-DE and 2-DE approach (Tables 2 and 4, Fig. 4), and are known to have participation in the classical, alternative and lectin pathways of complement activation. All of these proteins, except complement factor $\mathrm{H}$, were identified by 1-DE, while three were identified by 2-DE (C3, B and H) (Table 2, Figs. 3E and 4).

In relation to the two proteins identified both by 1-DE and 2-DE (C3 and B), similar positions were observed in the gels by comparing the respective molecular weights (Fig. 1). Complement C3 was identified between 40 and $55 \mathrm{kDa}$ (band 71 and spots 94, 95), while complement factor B was identified between 100 and $130 \mathrm{kDa}$ (band 5 and spot 23).

The complement factors $\mathrm{C} 3, \mathrm{~B}$ and $\mathrm{H}$, identified by 2-DE in our work, have also been identified in bovine blood serum (Wait et al., 2002; Talamo et al., 2003; Alonso-Fauste et al., 2012; Turk et al., 2012), in similar molecular weights (MW) and isoelectric point (pI). For instance, complement factor $\mathrm{H}$ has been identified in bovines at high MW, above serum albumin and at pI of approximately 6.0 (Turk et al., 2012), same position as identified in our work (near $170 \mathrm{kDa}$ and at pI of approximately 6.0).

Serpins (serine protease inhibitors) are the largest and most broadly distributed superfamily of protease inhibitors (Irving et al., 2000). In bovines, serpin A3-8 has already been shown to increase in milk whey of cows challenged with Streptococcus uberis, where concentrations were $20,158,246,283$ and 33 times higher at $36,42,57,81$ and $312 \mathrm{~h}$ postchallenge, respectively, when comparing to before challenge (Mudaliar et al., 2016). In this study, 4 different blood serum serpins related to defence/immunity (Serpin A3-2, Serpin A1/ $\alpha 1$-antitrypsin, Endopin 1b and Endopin 2B) were detected by using 1-DE, while 2-DE approach was not able to detect only Endopin 2B (Tables 2 and 4, Figs. 3E and 4). In relation to the three proteins identified both by 1-DE and 2-DE (Serpin A3-2, Serpin A1/a1-antitrypsin and Endopin 1b), Serpin A3-2 and Endopin 1b were identified near $130 \mathrm{kDa}$ (band 3 and spot 25), while Serpin A1/a1-antitrypsin was identified between 55 and $70 \mathrm{kDa}$ (band 9 and spot 32) (Fig. 1).

When comparing with studies performed with the 2-DE approach with bovine samples, Serpin A1/ $\alpha 1$-antitrypsin has also been identified in bovine blood serum (Wait et al., 2002; Talamo et al., 2003; AlonsoFauste et al., 2012; Turk et al., 2012) in similar molecular weights 


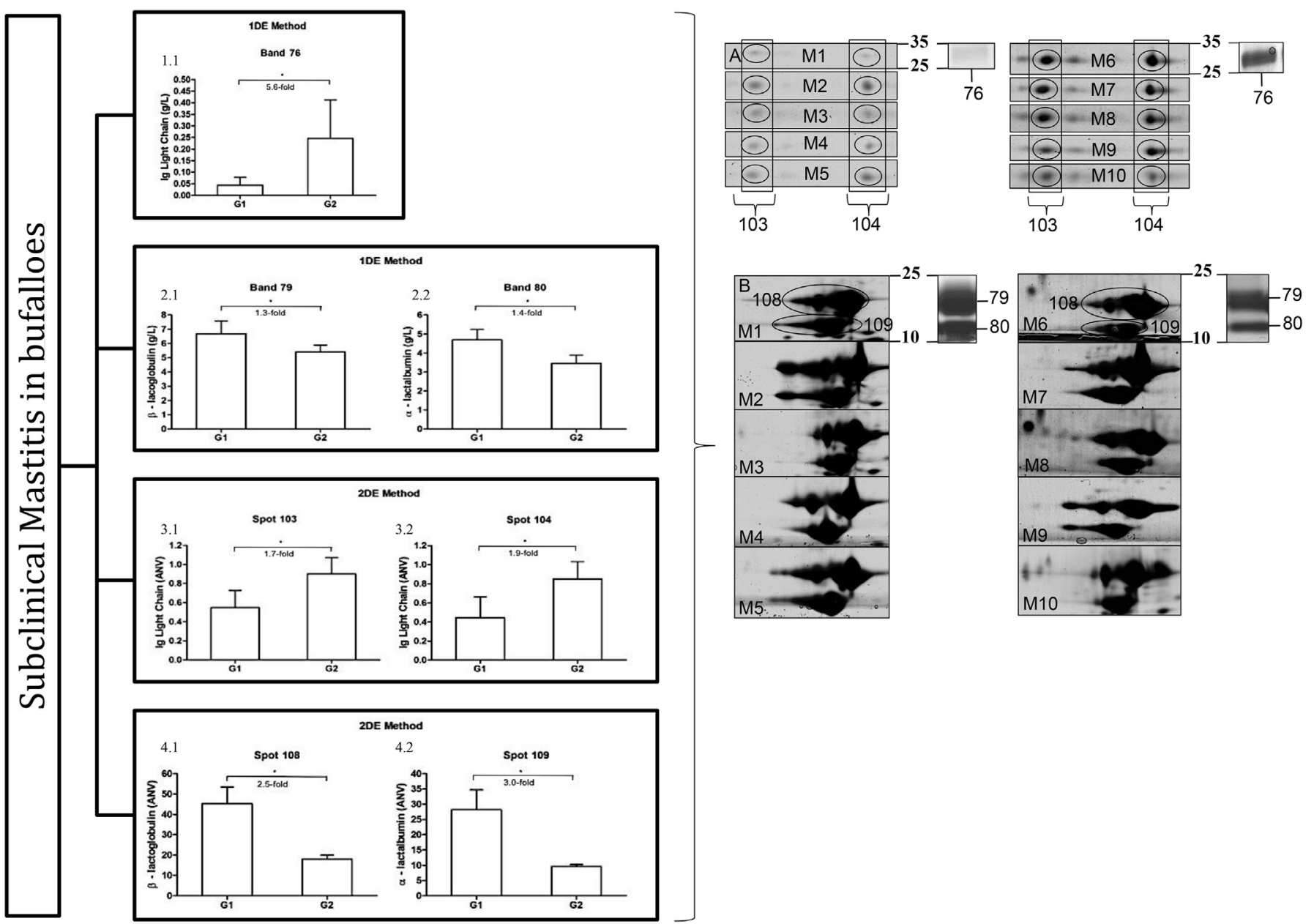

Fig. 6. Expanded 1-DE and 2-DE maps (right side) from healthy (M1, M2, M3, M4, M5) and mastitic (M6, M7, M8, M9, M10) milk whey samples showing alterations in intensity of spots $(103,104)$ and band $(76)$ identified as Ig Light Chain, and that were differentially expressed during mastitis as showed in grafics (left side: Panel 1.1, 3.1, 3.2). Expanded 2-DE maps from healthy (M1 to M5) and mastitic (M6 to M10) milk whey samples showing alterations in intensity of spots (108,109) and bands $(79,80)$ identified as $\beta$-lactoglobulin and $\alpha$-lactalbumin, respectively, that were differentially expressed during mastitis as showed in grafics (left side: Panel $2.1,2.2,4.1,4.2)$. * statistically significant $(\mathrm{p}<0.05)$. The displayed area corresponds to box A and B in Fig. 2.Information on bands/spots ID are in Table 2. $\mathrm{ANV}=$ Average Normalized Volume $\times 10^{6}$.

(MW) and isoelectric point (pI) then those identified in our work with buffaloes. However, although endopin $1 \mathrm{~b}$ has been identified in similar pI (around 5.0) when comparing to bovine (Alonso-Fauste et al., 2012), this protein was identified in higher MW in our work, being near to $130 \mathrm{kDa}$, against $45-67 \mathrm{kDa}$ in bovine as described by Alonso-Fauste et al. (2012).

\subsubsection{Identification of defence/immunity related proteins in the milk whey}

In this study, 15 milk whey defence/immunity related proteins were detected by using a combined 1-DE and 2-DE approach, coupled with LC/ESI-MS/MS, and among this class of proteins, important immunoglobulins, complement system proteins and serpins were identified (Tables 3 and 4, Figs. 3F and 4).

Ig $\mathrm{M}$ and Ig $\mathrm{G}$ are vital immunoglobulins for the complete function of humoral immunity and are also essential for the activation of the classical pathway of complement system (Nauta et al., 2004). In this context, 4 immunoglobulins (Ig M Heavy Chain, Ig Heavy Chain/Ig G1 Heavy Chain, Ig Light Chain and Ig J Chain) and 3 complement factors (C3, C4 and B) were identified in milk whey by using 1-DE and 2DE.The immunoglobulins and complement factor C3 were identified both by 1-DE and 2-DE, while complement factors $\mathrm{C} 4$ was only identified by 2-DE and complement factor B was only identified by 1-DE (Tables 3 and 4, Figs. 3F and 4).

Ig M Heavy Chain was identified between 70 and $100 \mathrm{kDa}$ (band 64, spots 82, 84), Ig Heavy Chain/Ig G1 Heavy Chain near 55 kDa (band 68 and spots 90, 92), Ig Light Chain near $25 \mathrm{kDa}$ (band 76 and spots 101 , 102, 103, 104) and Ig J Chain between 15 and $25 \mathrm{kDa}$ (band 78, spot 105) (Fig. 2), and were found to be in similar positions when compared to the described in bovine milk whey 2-DE gels using $7 \mathrm{~cm}$ IPG strips pH 4-7 for first dimension (Alonso-Fauste et al., 2012) and $18 \mathrm{~cm} \mathrm{IPG}$ strips pH 3-10 (Fong et al., 2008).

Complement factor C3 was identified between 40 and $55 \mathrm{kDa}$ (band 71 and spots 94, 95) (described in Section 3.1.2) and between 55 and $70 \mathrm{kDa}$ (bands 65, 66). In bovine milk whey, C3 was also found in similar position in 2-DE gels, between 37 and $75 \mathrm{kDa}$, using $11 \mathrm{~cm}$ IPG strips pH 3-10 (Boehmer et al., 2008), $18 \mathrm{~cm}$ IPG strips pH 3-10 (Fong et al., 2008) and $7 \mathrm{~cm}$ IPG strips pH 4-7 (Alonso-Fauste et al., 2012), but also was identified between 75 and $100 \mathrm{kDa}$ (Fong et al., 2008). Complement factor C4 was identified between 35 and $40 \mathrm{kDa}$ (spot 96), in different positions than identified by Fong et al. (2008) (75-100 kDa) and Boehmer et al. (2008) (20-25 kDa). These results related to C3 and C4 are expected since literature shows, by 2-DE and western blotting analysis, that these proteins can be identified in many positions in human blood plasma 2-DE gels (Michlmayr et al., 2010).

\subsubsection{Identification of proteins with other functions in blood serum and milk whey}

Other important proteins, related to protein, carbohydrate and lipid 
metabolism, development, transport, signaling, etc., were identified in blood serum and/or milk whey in 1-DE and 2-DE gels, and are named in Tables 2 and 3. In particular, especial attention is given to the high abundance proteins $\beta$-lactoglobulin and $\alpha$-lactalbumin, identified in the milk whey, and serum albumin (discussed in sessions Section 3.1.1 and Section 3.1.2), identified in the blood serum and milk whey.

Milk protein accounts for approximately 3.2 to $3.8 \%$ of milk components, consisting of about $80 \%$ caseins and $20 \%$ whey proteins with major components being $\alpha$-lactalbumin and $\beta$-lactoglobulin (Gellrich et al., 2014). Therefore, $\beta$-lactoglobulin and $\alpha$-lactalbumin account for about $45 \%$ and $15 \%$ of milk whey proteins (De Marchi et al., 2009) and are considered high abundance proteins in the milk whey. In this study, milk whey $\beta$-lactoglobulin and $\alpha$-lactalbumin were identified both by 1 DE and 2-DE approach (Tables 3 and 4, Figs. 3F and 4), and presented similar positions in the gels by comparing the respective molecular weights (Fig. 2), and were identified between 10 and $15 \mathrm{kDa}$ ( $\beta$-lactoglobulin: band 79 and spot 108; $\alpha$-lactalbumin: band 80 and spot 109).

Comparing to studies performed with bovine 2-DE approach (Smolenski et al., 2007; Boehmer et al., 2008; Fong et al., 2008; AlonsoFauste et al., 2012), $\beta$-lactoglobulin and $\alpha$-lactalbumin were in similar positions in the gels, between 10 and $25 \mathrm{kDa}$ and at a acidic pI.

\subsection{Changes in protein patterns during salmonellosis and mastitis}

Milk whey and blood serum are complex mixtures of a few high abundance proteins and a wide selection of low abundance protein components that could be utilized for diagnosis and prognosis purposes. In this sense, the use of proteomic methodologies to obtain a more complete and unbiased characterization of host responses during infections could lead to the identification of a pattern of biomarkers indicative of diseases (Ferreira et al., 2013).

Therefore, additionally from defining a reference map for 1-DE and 2-DE, examples of changes in protein patterns in the blood serum of buffalo calves during salmonellosis (Table 5, Fig. 5) and milk whey of lactating buffaloes during mastitis (Table 5, Fig. 6), to identify possible applications of proteins identified in the reference maps produced in our work, are also presented in this study.

\subsubsection{Changes in protein patterns during salmonellosis}

The first month of life is critical for newborns buffalo calves and morbidity and mortality rates are high, especially due to diarrhea and pneumonia (Khan et al., 2009; Anwarullah et al., 2014; Naag et al., 2015). In this context, Salmonella spp. have been reported worldwide in buffalo calves, associated with diarrhea and gastroenteritis (Borrielo et al., 2012; Anwarullah et al., 2014). Therefore, considering the importance of salmonellosis in buffalo calves, we have chosen to show some alterations in expression patterns of $\beta$-haptoglobin and $\alpha$-haptoglobin fractions linked to this disease.

Experimental infection using $10^{8} \mathrm{CFU}$ of S. Dublin was able to promote hyperthermia and diarrhea $72 \mathrm{~h}$ after inoculation, two important clinical signs of salmonellosis. Also, $S$. Dublin was isolated in the feces $72 \mathrm{~h}$ post-infection, confirming that the experimental infection was effective (Table 1). Expression patterns of $\beta$-haptoglobin (spots 39 and 40, band 14) and $\alpha$-haptoglobin fractions (spots 38 and 45, band 18) comparing blood samples from buffalo calves experimentally infected with $S$. Dublin before (M0) and $72 \mathrm{~h}$ after inoculation (M1) were analyzed, and results showed that the expression of these two fractions were significantly up-regulated $72 \mathrm{~h}$ post-infection (M1), in both 1-DE and 2-DE analysis (Table 5, Fig. 5). Moreover, these patterns were validated by performing a hemoglobin binding method (Eckersall et al., 1999) to measure haptoglobin concentrations in the blood serum, which also showed significantly higher concentrations of this protein $72 \mathrm{~h}$ post-infection (Table 5, Fig. 5).

Increased concentrations of haptoglobin in S. Dublin infected buffalo calves presented in our work were expected, since major increase of this important APP have already been shown in the blood serum of buffalo calves during S. Typhimurium experimental infection (Clemente et al., 2016) and in 3 to 11 month old buffaloes naturally infected with dermatophytosis (Kabu and Sayin, 2016), among other studies involving adult buffaloes, where blood serum concentrations of haptoglobin in animals with traumatic reticuloperitonitis (El-Ashker et al., 2013) and animals experimentally infected with Pasteurella multocida (Horadagoda et al., 2001, 2002) were also increased.

\subsubsection{Changes in protein patterns during mastitis}

Studies have shown that the prevalence rate of subclinical mastitis in lactating buffaloes can be high (Costa et al., 2000; Dhakal, 2006; Sharif and Ahmad, 2007), and therefore reliable and early detection of subclinical mastitis is necessary for disease control and monitoring of milk quality (Pyörälä et al., 2011).

Therefore, since mastitis affects lactating buffaloes and can contribute to lower milk productivity, alterations in expression patterns of immunoglobulin light chain (IgLC) (spots 103 and 104, band 76) and $\beta$ lactoglobulin (spot 108, band 79) and $\alpha$-lactalbumin (spot 109, band 80) comparing samples from healthy buffaloes (G1) and buffaloes with subclinical mastitis (G2) were analyzed in our work. Results showed that, both in 1-DE and 2-DE analysis, the expression of band/spots identified as IgLC were significantly up-regulated during mastitis (G2), while the expression of band/spots identified as $\beta$-lactoglobulin and $\alpha$ lactalbumin were significantly down-regulated during mastitis (G2) (Table 5, Fig. 6). $\beta$-lactoglobulin and $\alpha$-lactalbumin have already been described as decreased in bovines during mastitis (Hogarth et al., 2004; Boehmer et al., 2008; Smolenski et al., 2014) due to mammary gland tissue destruction (Hogarth et al., 2004; Pyörälä, 2003), which is expected since these proteins are produced in the mammary gland tissue.

\subsection{Final remarks}

A combined approach based on 1-DE and 2-DE coupled with LC/ ESI-MS/MS resulted in a blood serum protein map with 37 different identified proteins in buffalo-calves and in a milk whey protein map with 42 different identified proteins in lactating buffaloes. Therefore, the establishment of these protein maps using 1-DE and 2-DE technique has led to the identification of important disease-related proteins that will help to address alterations during diseases and other physiological conditions in buffaloes.

Additionally, significant changes in patterns of haptoglobin were observed in buffalo calves with salmonellosis, while significant changes in patterns of immunoglobulin light chain, $\beta$-lactoglobulin and $\alpha$-lactalbumin where observed in lactating buffaloes during mastitis. This shows the importance of studying protein alterations during diseases and highlighting the potential of 1-DE and 2-DE technique to identify pattern of biomarkers indicative of diseases during host responses.

\section{Acknowledgements}

Funding: This work was supported by São Paulo Research Foundation (FAPESP) [Grant process number: \#2008/50388-7, \#2009/ 12350-0, \#2012/10094-0, \#2013/26498-5]; University of Glasgow; Wellcome Trust [grant no. 097821/Z/11/Z]; Suzanne McGill, Christina Naula (Glasgow Polyomics) and Chris McComb (University of Glasgow) are thanked for technical assistance.

\section{References}

Alonso-Fauste, I., Andres, M., Iturralde, M., Lampreave, F., Gallart, J., Alava, M.A., 2012. Proteomic characterization by 2-DE in bovine serum and whey from healthy and mastitis affected farm animals. Proteomics 75, 3015-3030.

Anwarullah, M., Khan, J.A., Khan, M.S., Ashraf, K., Avais, M., 2014 Prevalence of Salmonella and Escherichia coli associated with diarrhea in buffalo and cow calves. Buffalo Bull. 33, 332-336.

Ballanti, E., Perricone, C., Muzio, G., Kroegler, B., Chimenti, M.S., Graceffa, D., Perricone, R., 2011. Role of the complement system in rheumatoid arthritis and psoriatic 
arthritis: relationship with anti-TNF inhibitors. Autoimmun. Rev. 10, 617-623.

Boehmer, J.L., Bannerman, D.D., Shefcheck, K., Ward, J.L., 2008. Proteomic analysis of differentially expressed proteins in bovine milk during experimentally induced Escherichia coli mastitis. J. Dairy Sci. 91, 4206-4218.

Boehmer, J.L., Degrasse, J.A., McFarland, M.A., Tall, E.A., Shefcheck, K.J., Ward, J.L., 2010a. The proteomic advantage: label-free quantification of proteins expressed in bovine milk during experimentally induced coliform mastitis. Vet. Immunol. Immunopathol. 138, 252-266.

Boehmer, J.L., Ward, J.L., Peters, R.R., Shefcheck, K.J., Mcfarland, M.A., Bannerman, D.D., 2010b. Proteomic analysis of the temporal expression of bovine milk proteins during coliform mastitis and label-free relative quantification. J. Dairy Sci. 93, 593-603.

Borrielo, G., Lucibelli, M.G., Pesciaroli, M., Carullo, M.R., Graziani, C., Ammendola, S., Battistoni, A., Ercolini, D., Pasquali, P., Galiero, G., 2012. Diversity of Salmonella spp. serovars isolated from the intestines of water buffalo calves with gastroenteritis. BMC Vet. Res. 8, 201.

Buitenhuis, B., Rontved, C.M., Edwards, S.M., Ingvartsen, K.L., Sorensen, P., 2011. In depth analysis of genes and pathways of the mammary gland involved in the pathogenesis of bovine Escherichia coli-mastitis. BMC Genomics 12, 130. http://dx.doi. org /10.1186/1471-2164-12-130.

Ceciliani, F., Ceron, J.J., Eckersall, P.D., Sauerwein, H., 2012. Acute phase proteins in ruminants. J. Proteome 75, 4207-4231.

Chiaradia, E., Avellini, L., Tartaglia, M., Gaiti, A., Just, I., Scoppetta, F., Czentnar, Z., Pich, A., 2012. Proteomic evaluation of sheep serum proteins. BMC Vet. Res. 8, 66.

Clemente, V., Santana, A.M., Silva, D.G., Silveira, C.R.A., Pizauro, L.J.L., Clemente, Z., Fagliari, J.J., 2016. Acute phase response in buffalo calves experimentally infected with Salmonella typhimurium. Pak. Vet. J. 36, 153-158.

Costa, E.O., Watanabe, E.T., Ribeiro, A.R., Garino, J.R.F., Houriti, A.M., Baruselli, P.S., 2000. Buffalo mastitis: etiology and clinical and subclinical mastitis rates. Napgama $1,12-15$.

D'Ambrosio, C., Arena, S., Salzano, A.M., Renzone, G., Ledda, L., Scaloni, A., 2008. A proteomic characterization of water buffalo milk fractions describing PTM of major species and the identification of minor components involved in nutrient delivery and defense against pathogens. Proteomics 8, 3657-3666.

Daneshvar, H., Wyllie, S., Phillips, S., Hagan, P., Burchmore, R., 2012. Comparative proteomics profiling of a gentamicin-attenuated Leishmania infantum cell line identifies key changes in parasite thiol-redox metabolism. Proteomics 75, $1463-1471$.

Danielsen, M., Codrea, M.C., Ingvartsen, K.L., Friggens, N.C., Bendixen, E., Rontved, C.M., 2010. Quantitative milk proteomics: host responses to LPS mediated inflammation of bovine mammary gland. Proteomics 10, 2240-2249.

D'Auria, E., Agostoni, C., Giovannini, M., Riva, E., Zetterstrom, R., Fortin, R., Greppi, G.F., Bonizzi, L., Roncada, P., 2005. Proteomic evaluation of milk from different mammalian species as a substitute for breast milk. Acta Paediatr. 94, 1708-1713.

De Marchi, M., Bonfatti, V., Cecchinato, A., Di Martino, G., Carnier, P., 2009. Prediction of protein composition of individual cow milk using mid-infrared spectroscopy. Ital. J. Anim. Sci. 8, 399-401.

Dhakal, I.P., 2006. Normal somatic cell count and subclinical mastitis in Murrah buffaloes. J. Vet. Med. 53, 81-86.

Eckersall, P.D., Bell, R., 2010. Acute phase proteins: biomarkers of infection and inflammation in veterinary medicine. Vet. J. 185, 23-27.

Eckersall, P.D., Duthie, S., Safi, S., Moffatt, D., Horadagoda, N.U., Doyle, S., Parton, R., Bennett, D., Fitzpatrick, J.L., 1999. An automated biochemical assay for haptoglobin: prevention of interference from albumin. Comp. Haematol. Int. 9, 117-124.

Eckersall, P.D., Young, F.J., McComb, C., Hogarth, C.J., Safi, S., Weber, A., McDonald, T., Nolan, A.M., Fitzpatrick, J.L., 2001. Acute phase proteins in serum and milk from dairy cows with clinical mastitis. Vet. Rec. 148, 35-41.

Eckersall, P.D., Young, F.J., Nolan, A.M., Knight, C.H., McComb, C., Waterston, M.M., Hogarth, C.J., Scott, E.M., Fitzpatrick, J.L., 2006. Acute phase proteins in bovine milk in an experimental model of Staphylococcus aureus subclinical mastitis. J. Dairy Sci. 89, 1488-1501.

El-Ashker, M., Salama, M., El-Boshy, M., 2013. Traumatic reticuloperitonitis in wate buffalo (Bubalus bubalis): clinical findings and the associated inflammatory response. J. Vet. Med. http://dx.doi.org/10.1155/2013/808656.

Fecteau, M.E., House, J.K., Kotarski, S.F., Tankersley, N.S., Ontiveros, M.M., Alcantar, C.R., Smith, B.P., 2003. Efficacy of ceftiofur for treatment of experimental salmonellosis in neonatal calves. Am. J. Vet. Res. 64, 918-925.

Ferreira, A.M., Bislev, S.L., Bendixen, E., Almeida, A.M., 2013. The mammary gland in domestic ruminants: a systems biology perspective. Proteomics 94, 110-123.

Fong, B.Y., Norris, C.S., Palmano, K.P., 2008. Fractionation of bovine whey proteins and characterisation by proteomic techniques. Int. Dairy J. 18, 23-46.

Gellrich, K., Meyer, H.H.D., Wiedemann, S., 2014. Composition of major proteins in cow milk differing in mean protein concentration during the first 155 days of lactation and the influence of season as well as short-term restricted feeding in early and midlactation. Czech J. Anim. Sci. 59, 97-106.

Hogarth, C.J., Fitzpatrick, J.L., Nolan, A.M., Young, F.J., Pitt, A., Eckersall, P.D., 2004. Differential protein composition of bovine whey: a comparison of whey from healthy animals and from those with clinical mastitis. Proteomics 4, 2094-2100.

Horadagoda, N.U., Hodgson, J.C., Moon, G.M., Wijewardana, T.G., Eckersall, P.D., 2001. Role of endotoxin in the pathogenesis of haemorrhagic septicaemia in the buffalo. Microb. Pathog. 30, 171-178.

Horadagoda, N.U., Hodgson, J.C., Moon, G.M., Wijewardana, T.G., Eckersall, P.D., 2002. Development of a clinical syndrome resembling haemorrhagic septicaemia in the buffalo following intravenous inoculation of Pasteurella multocida serotype B:2 endotoxin and the role of tumour necrosis factor- $\alpha$. Res. Vet. Sci. 72, 194-200.

Irving, J.A., Pike, R.N., Lesk, A.M., Whisstock, J.C., 2000. Phylogeny of the serpin superfamily: implications of patterns of amino acid conservation for structure and function. Genome Res. 10, 1845-1864.

Jena, M.K., Janjanama, J., Narub, J., Kumard, S., Kumara, S., Singha, S., Mohapatraa, S.K., Kolac, S., Ananda, V., Jaswala, S., Vermaa, A.K., Malakara, D., Danga, A.K., Kaushika, J.K., Reddyd, V.S., Mohantya, A.K., 2015. DIGE based proteome analysis of mammary gland tissue in water buffalo (Bubalus bubalis): lactating vis-a-vis heifer. J. Proteome 119, 100-111.

Jorgensen, J.H., Pfaller, M.A., Carroll, K.C., Funke, G., Landry, M.L., Richter, S.S., Warnock, D.W., 2015. Manual of Clinical Microbiology, 11th ed. http://dx.doi.org/ $10.1128 / 9781555817381$.

Kabu, M., Sayin, Z., 2016. Concentrations of serum amyloid a, haptoglobin, tumour necrosis factor and interleukin-1 and -6 in Anatolian buffaloes naturally infected with dermatophytosis. Vet. Med. (Praha) 61, 133-135.

Khan, J.A., Khan, M.S., Khan, M.A., Avais, M., Maqbool, A., Salman, M., Rehman, Z.U., 2009. Epidemiology of major bacterial and viral causes of diarrhea in buffalo calves in three districts of the Punjab province of Pakistan. J. Zool. (Lond.) 9, 187-193.

Kumar, P., Sharma, A., Sindhu, N., Deora, A., 2014. Acute phase proteins as indicators of inflammation in streptococcal and staphylococcal mastitis in buffaloes. Haryana Vet. $53,46-49$.

Michlmayr, A., Bachleitner-Hofmann, T., Baumann, S., Marchetti-Deschmann, M., RechWeichselbraun, I., Burghuber, C., Pluschnig, U., Bartsch, R., Graf, A., Greil, R., Allmaier, G., Steger, G., Gnant, M., Bergmann, M., Oehler, R., 2010. Modulation of plasma complement by the initial dose of epirubicin/docetaxel therapy in breast cancer and its predictive value. Br. J. Cancer 103, 1201-1208.

Miles, A.A., Misra, S.S., 1938. The estimation of the bactericidal power of the blood. J. Hyg. (Lond) 38, 732-749.

Ministry of Agriculture, Livestock and Food Supply (MAPA), 2016. http://www. agricultura.gov.br/arq_editor/file/Dados\%20de\%20rebanho\%20bovino\%20e \%20bubalino\%20do\%20Brasil\%202014.pdf, Accessed date: 12 October 2016.

Mudaliar, M., Tassi, R., Thomas, F.C., McNeilly, T.N., Weidt, S.K., McLaughlin, M., Wilson, D., Burchmore, R., Herzyk, P., Eckersall, P.D., Zadoks, R.N., 2016. Mastitomics, the integrated omics of bovine milk in an experimental model of Streptococcus uberis mastitis: 2 . Label-free relative quantitative proteomics. Mol. BioSyst. 12, 2748-2761.

Naag, D., Swamy, M., Shrivastav, A.B., 2015. Enteric parasitic infection in diarrheic buffalo calves. Buffalo Bull. 34, 223-225.

Nauta, A.J., Castellano, G., Xu, W., Woltman, A.M., Borrias, M.C., Daha, M.R., van Kooten, C., Roos, A., 2004. Opsonization with C1q and mannose-binding lectin targets apoptotic cells to dendritic cells. J. Immunol. 173, 3044-3050.

Pyörälä, S., 2003. Indicators of inflammation in the diagnosis of mastitis. Vet. Res. 34, 565-578.

Pyörälä, S., Hovinen, M., Simojoki, H., Fitzpatrick, J., Eckersall, P.D., Orro, T., 2011. Acute phase proteins in milk in naturally acquired bovine mastitis caused by differen pathogens. Vet. Rec. 168, 535. http://dx.doi.org/10.1136/vr.d1120.

Quinn, P.J., Carter, M.E., Markey, B., 1994. Clinical Veterinary Microbiology. Wolfe, London (648p).

Quinn, P.J., Markey, B., Carter, M.E., Donnelly, W.J., Leonard, F.C., 2005. Microbiologia veterinária e doenças infecciosas. Artm ed, Porto Alegre (512p).

Santos, R.L., Tsolis, R.M., Bäumler, A.J., Adams, L.G., 2002. Hematologic and serum biochemical changes in salmonella ser Typhimurium-infected calves. Am. J. Vet. Res. $63,1145-1150$.

Schiess, R., Wollscheid, B., Aebersold, R., 2009. Targeted proteomic strategy for clinical biomarker discovery. Mol. Oncol. 3, 33-44.

Sharif, A., Ahmad, T., 2007. Prevalence of severity of mastitis in buffaloes in district Faisalabad (Pakistan). J. Agric. Soc. Sci. 3, 34-36.

Silva, D.G., Santana, A.M., Pizauro, L.J.L., Bernardes, P.A., Clemente, V., Silveira, C.R.A., Christoforo, M.T., Fagliari, J.J., 2015. Toxocara vitulorum in newborn buffalo calves. Investigação 14, 102-104.

Smolenski, G., Haines, S., Kwan, F., Bond, J., Farr, V., Davis, S., Stelwagen, K., Wheeler, T., 2007. Characterisation of host defence proteins in milk using a proteomic approach. J. Proteome Res. 6, 207-215.

Smolenski, G.A., Broadhurst, M.K., Stelwagen, K., Haigh, B.J., Wheeler, T.T., 2014. Host defence related responses in bovine milk during an experimentally induced streptococcus uberis infection. Proteome Sci. 12, 19.

Takahashi, E., Kuwayama, H., Kawamoto, K., Matsui, T., Inokuma, H., 2009. Detection of serum amyloid A isoforms in cattle. J. Vet. Diagn. Investig. 21, 874-877.

Talamo, F., D'Ambrosio, C., Arena, S., Del Vecchio, P., Ledda, L., Zehender, G., Ferrara, L., Scaloni, A., 2003. Proteins from bovine tissues and biological fluids: defining a reference electrophoresis map for liver, kidney, muscle, plasma and red blood cells. Proteomics 3, 440-460.

Thomas, F.C., Mudaliar, M., Tassi, R., McNeilly, T.N., Burchmore, R., Burgess, K., Herzyk, P., Zadoks, R.N., Eckersall, P.D., 2016a. Mastitomics, the integrated omics of bovine milk in an experimental model of Streptococcus uberis mastitis: 3. Untargeted metabolomics. Mol. BioSyst. 12, 2762-2769.

Thomas, F.C., Mullen, W., Tassi, R., Ramírez-Torres, A., Mudaliar, M., McNeilly, T.N., Zadoks, R.N., Burchmore, R., Eckersall, P.D., 2016b. Mastitomics, the integrated omics of bovine milk in an experimental model of Streptococcus uberis mastitis: 1. High abundance proteins, acute phase proteins and peptidomics. Mol. BioSyst. 12, 2735-2747.

Trabulsi, L.R., Ordoñez, J.G., Martinez, M.B., 2005a. Enterobacteriaceae. In: Trabulsi, L.R., Alterthum, F. (Eds.), Microbiologia, 4th ed. Atheneu, São Paulo, pp. 269-276.

Trabulsi, L.R., Teixeira, L.M., Bueris, V., 2005b. Staphylococcus aureus. In: Trabulsi, L.R., Alterthum, F. (Eds.), Microbiologia, 4th ed. Atheneu, São Paulo, pp. 175-182.

Tremblay, R.R., 1990. Intravenous fluid therapy in calves. Vet. Clin. N. Am. Food Anim. Pract. 6, 77-101.

Turk, R., Piras, C., Kovačić, M., Samardžija, M., Ahmed, H., De Canio, M., Urbani, A., 
Meštrić, Z.F., Soggiu, A., Bonizzi, L., Roncada, P., 2012. Proteomics of inflammatory and oxidative stress response in cows with subclinical and clinical mastitis. J. Proteome 75, 4412-4428.

Wait, R., Miller, I., Eberini, I., Cairoli, F., Veronesi, C., Battocchio, M., Gemeiner, M., Gianazza, E., 2002. Strategies for proteomics with incompletely characterized genomes: the proteome of Bos taurus serum. Electrophoresis 23, 3418-3427.

Wenz, J.R., Fox, L.K., Muller, F.J., Rinaldi, M., Zeng, R., Bannerman, D.D., 2010. Factors associated with concentrations of select cytokine and acute phase proteins in dairy cows with naturally occurring clinical mastitis. J. Dairy Sci. 93, 2458-2470. 